\title{
The Relationship between Weight Bias Internalization and \\ Healthy and Unhealthy Weight Control Behaviours
}

\author{
Matthew Levy
}

A Thesis

in

The Department

of

Health, Kinesiology and Applied Physiology

Presented in Partial Fulfilment of the Requirements

for the Degree of Master of Science (Exercise Science) at

Concordia University

Montreal, Quebec, Canada

July 2020

(C) Matthew Levy, 2020 


\section{CONCORDIA UNIVERSITY}

\section{School of Graduate Studies}

This is to certify that the thesis prepared

By: $\quad$ Matthew Levy

Entitled: The Relationship between Weight Bias Internalization and Healthy and Unhealthy Weight Control Behaviours

and submitted in partial fulfilment of the requirements for the degree of

\section{Master of Science (Health, Kinesiology and Applied Physiology)}

complies with the regulations of the University and meets the accepted standards with respect to originality and quality.

Signed by the final Examining Committee:

Chair

Dr. Richard DeMont

Co-supervisor

Dr. Lisa Kakinami

Examiner

Dr. Simon Bacon

Supervisor

Dr. Angela Alberga

Approved by

Dr. Geoffrey Dover

Dr. Pascale Sicotte

Date 


\section{ABSTRACT \\ The Relationship between Weight Bias Internalization \\ and \\ Healthy and Unhealthy Weight Control Behaviours}

\section{Matthew Levy}

Introduction: Weight bias internalization (WBI) is associated with disordered eating symptomology and motivation to control weight. However, the relationship between WBI and specific weight control behaviours and how these behaviours differ between men and women is not well understood. Weight perception has also been shown to be associated with weight control, but has been understudied in adult populations. The objectives of this study were to determine (1) the relationship between WBI and weight control behaviours, (2) whether weight perception is independently associated with weight control behaviours and (3) whether these relationships differ between sexes.

Methods: Canadian adults $(\mathrm{N}=161 ; 52.8 \%$ women; mean body mass index $[\mathrm{BMI}]=26.5 \pm 4.99$ $\mathrm{kg} / \mathrm{m}_{2}$ ) completed questionnaires pertaining to WBI, weight control behaviours (healthy, unhealthy, extreme) and weight perception (accurate, under-, or over-estimation compared with objectively measured BMI). The cross-sectional relationship between (1) WBI or (2) weight perception with the total number of healthy and unhealthy or extreme weight control behaviours, and likelihood of performing specific weight control behaviours were assessed with linear and logistic regression models, respectively. These regression models were adjusted for age, sex, race and weight perception. Subsequent analyses were stratified by sex.

Results: WBI was associated with an increased likelihood of performing exercise for weight control in the full sample $(\mathrm{OR}=2.20, \mathrm{p}<0.05)$; increased likelihood of skipping meals in women $(\mathrm{OR}=2.51, \mathrm{p}<0.01)$, and consuming little amounts of food in $\operatorname{men}(\mathrm{OR}=2.33, \mathrm{p}<0.01)$. Weight perception was not associated with weight control behaviours.

Conclusions: WBI was associated with various weight control behaviours and differed by sex. This study highlights WBI and its relationship with weight control behaviours. Future longitudinal research should be conducted to further understand the behavioural and health effects of WBI. 


\section{ACKNOWLEDGMENTS}

Completion of my M.Sc. thesis would not have been possible without the help and support of the following people:

I would like to express my deep appreciation to my supervisor, Dr. Angela Alberga for her support and guidance throughout this journey. Thank you for providing me with opportunities to grow as a young academic and for motivating me to mature as an individual. I also would like to sincerely thank Dr. Lisa Kakinami for stepping in as my co-supervisor during the past year. I could not have completed this thesis without your support, knowledge and patience. Thank you for tolerantly helping me with my stats questions and encouraging me to be resourceful and independent. I am so lucky to have had both of you on my team; I know that my thesis was greatly improved by your expertise and constant support. I really look forward to keeping in touch in the future.

My special thanks are extended to Dr. Simon Bacon for your knowledgeable contributions and suggestions that led to the improvement of my project. Thank you for also giving me the opportunity to gain exposure at the MBMC early on in my M.Sc. journey.

To my lab colleagues (Erica, Iyoma, Trisha, Kimiya, and Vida), it has been an amazing experience getting to know you, working with you and becoming friends. Thank you for making the lab feel like home. I hope we all stay in touch and I wish you all the best of luck in the future.

To my family and friends, thank you so much for your unconditional support, love and encouragement throughout this process. Thank you to BBN for making every day hilarious. What started out as spam mail has turned into a brotherhood. I'd also like to thank my incredible girlfriend Jacky for always supporting and listening to me; thank you for making every single day better. Finally, I'd like to thank my Mom for always believing in me and pushing me to be better. I could not have gotten through these past two years without you. You're the strongest person I know and I'm so lucky to have you in my life. 


\section{AUTHOR CONTRIBUTIONS}

Roles of co-authors:

Conception and Design: Matthew Levy, Angela S. Alberga, and Lisa Kakinami

Data Analysis: Matthew Levy

Data Interpretation: Matthew Levy, Angela S. Alberga, and Lisa Kakinami

Edit/draft of manuscript: Matthew Levy, Angela S. Alberga, and Lisa Kakinami 


\section{LIST OF TABLES}

Table 1: Sample Characteristics

Table 2: Multiple Linear Regressions: WBI and Healthy Weight Control Behaviours .35

Table 3: Multiple Logistic Regressions: WBI and Healthy Weight Control Behaviours .36

Table 4: Multiple Linear \& Logistic Regressions: WBI and Unhealthy \& Extreme Weight

Control Behaviours

Table 5: Multiple Logistic Regressions: WBI and Unhealthy Weight Control Behaviours .38

Table 6: Sensitivity Analysis - Distribution of Participants within 1kg/m2 of each BMI Classification Cut-Off.

Table 7: Sensitivity Analysis - Multiple Linear Regressions: WBI and Healthy Weight Control Behaviours $(\mathrm{N}=113)$.

Table 8: Sensitivity Analysis - Multiple Linear Regressions: Multiple Logistic Regressions: WBI and Healthy Weight Control Behaviours $(\mathrm{N}=113)$

Table 9: Sensitivity Analysis - Multiple Logistic Regressions: Multiple Linear Regressions: WBI and Unhealthy \& Extreme Weight Control Behaviours $(\mathrm{N}=113)$ .43

Table 10: Sensitivity Analysis - Multiple Logistic Regressions: WBI and Unhealthy Weight Control Behaviours $(\mathrm{N}=113)$ 


\section{TABLE OF CONTENTS}

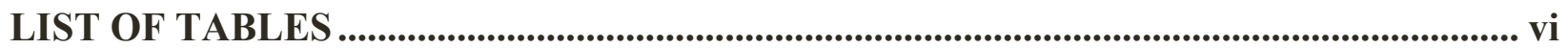

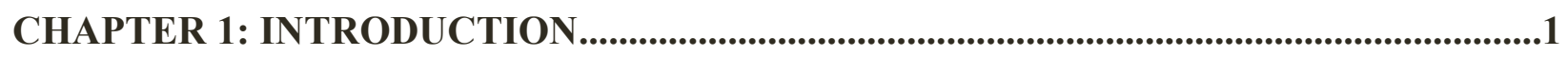

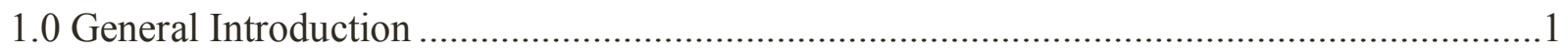

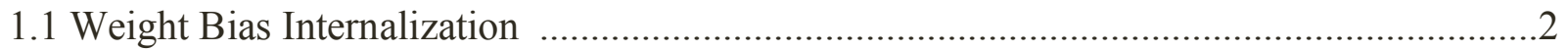

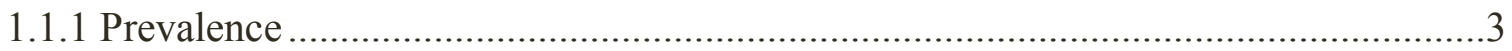

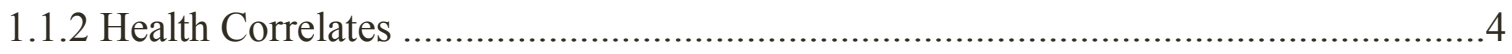

1.1.3 Relationship with Weight Control Behaviours ...................................................5

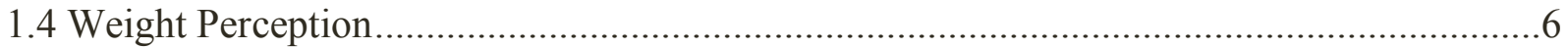

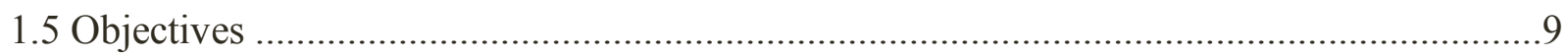

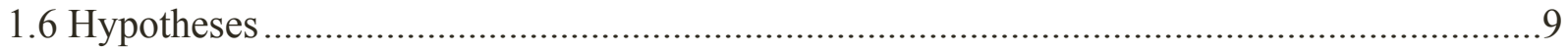

CHAPTER 2: METHODS .....................................................................................................10

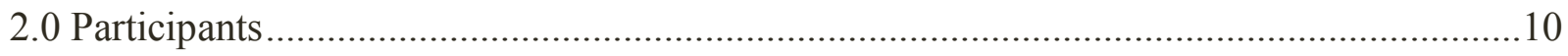

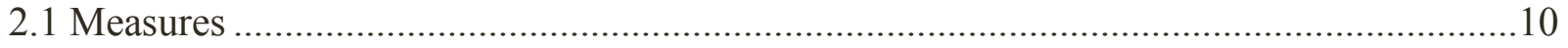

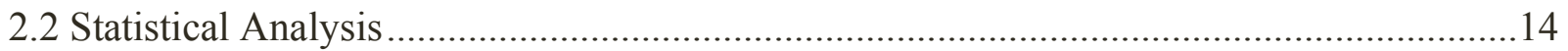

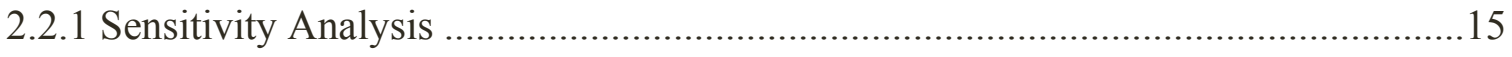

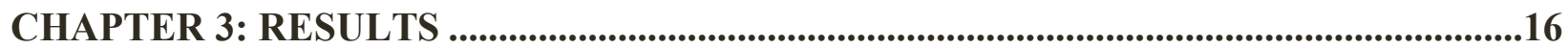

3.0 Manuscript: The Relationship between Weight Bias Internalization and Healthy and Unhealthy Weight Control Behaviours.......................................................................... 16

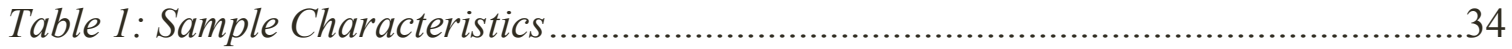

Table 2: Multiple Linear Regressions: WBI and Healthy Weight Control Behaviours ....35

Table 3: Multiple Logistic Regressions: WBI and Healthy Weight Control Behaviours ..36 Table 4: Multiple Linear \& Logistic Regressions: WBI and Unhealthy \& Extreme Weight Control Behaviours.....

Table 5: Multiple Logistic Regressions: WBI and Unhealthy Weight Control Behaviours 
3.11 Sensitivity Analysis Results.

3.2 Additional Results Tables from Sensitivity Analysis

Table 6: Sensitivity Analysis - Distribution of Participants within $1 \mathrm{~kg} / \mathrm{m} 2$ of each BMI

Classification Cut-Off.

Table 7: Sensitivity Analysis - Multiple Linear Regressions: WBI and Healthy Weight

Control Behaviours $(N=113)$.

Table 8: Sensitivity Analysis - Multiple Linear Regressions: Multiple Logistic

Regressions: WBI and Healthy Weight Control Behaviours $(N=113)$

Table 9: Sensitivity Analysis - Multiple Logistic Regressions: Multiple Linear

Regressions: WBI and Unhealthy \& Extreme Weight Control Behaviours $(N=113)$.

Table 10: Sensitivity Analysis - Multiple Logistic Regressions: WBI and Unhealthy

Weight Control Behaviours $(N=113)$.

CHAPTER 4: DISCUSSION

CHAPTER 5: CONCLUSION.

REFERENCES.

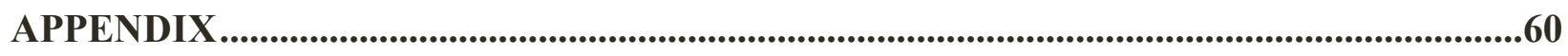

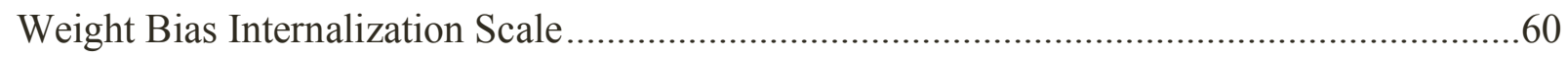

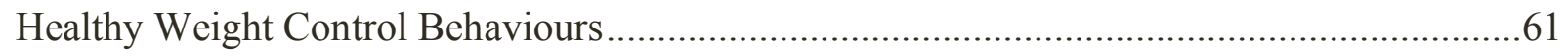

Unhealthy \& Extreme Weight Control Behaviours .........................................................61

Proof of Manuscript Submission to Obesity Facts ..............................................................62 


\section{CHAPTER 1: INTRODUCTION}

\subsection{General Introduction}

As the prevalence of overweight and obesity has increased and has been projected to increase in Canada (1), the level of weight bias appears to be rising concomitantly (2). Weight bias, defined as holding negative or stereotypical attitudes towards individuals because of their weight, is present in all sectors of society, such as in employment, education, healthcare and familial settings (3). Weight bias is also pervasive in our media and culture, such as in television $(4,5)$, popular social media platforms (6) and newspapers (7). Some of these negative stereotypes include that: individuals with overweight and obesity are lazy, unmotivated, incompetent, noncompliant, sloppy, and lack self-discipline (3). Experiencing weight bias is associated with various behaviours, as well as several negative physical and mental health measures, such as weight gain (8), anxiety, depression, eating disturbances (9), increased food consumption, and reduced physical activity (10). Researchers have highlighted the importance of recognising the adverse health consequences associated with weight bias and encouraging interventions to reduce weight bias throughout society (11).

Alongside the increase in weight bias research, there has been interest in investigating the self-directed aspect of weight bias, referred to as 'weight bias internalization' (WBI) (12). WBI arises when individuals agree with the negative stereotypes surrounding individuals with overweight and obesity, and internalize these attitudes to the detriment of their own self-efficacy or social adequacy (13). For instance, agreeing with statements such as "my weight is a major way that I judge my value as a person" (14), would be indicative of experiencing feelings of WBI. The first journal article describing WBI was published in 2008, in which researchers developed a scale to measure WBI (14). Since then, there has been an exponential increase in published research focusing on the prevalence of WBI as well as the various health-related correlates associated with experiencing WBI, as outlined in a 2018 systematic review by Pearl and Puhl (12). Although general aspects of the WBI literature will be outlined in the following sections, gaps in the literature still remain. 


\subsection{Weight Bias Internalization}

\subsubsection{Weight Bias Internalization: Prevalence}

The prevalence of WBI has not been reported in Canadian samples of adults, however it has been reported among individuals living in the United States. In a national sample of U.S. adults with and without overweight and obesity $(\mathrm{N}=3,504 ; 56.4 \%$ women; body mass index $[\mathrm{BMI}]=28.11 \pm 7.33 \mathrm{~kg} / \mathrm{m} 2), 23 \%$ of participants experienced high levels of WBI (defined as one standard deviation above the mean) (15). In a large sample of members of the commercial weight management program Weight Watchers $(\mathrm{N}=18,769 ; 94.6 \%$ women; $\mathrm{BMI}=31.90 \pm 7.00 \mathrm{~kg} / \mathrm{m} 2)$, $35.3 \%$ of participants were classified as having high WBI (16). Several studies have demonstrated that WBI is prevalent in both men and women; however, it has been shown to be both more common and more severe among women compared to men (12,15-20). For example, in the aforementioned study examining a national sample of U.S. adults with and without overweight and obesity, the proportion of females to males was higher as the level of WBI increased. More specifically, 47.4\% with low WBI (one standard deviation below the mean) were women, $53.1 \%$ with average WBI were women, and $72.1 \%$ with high WBI were women (15). Most studies explicitly recruited participants with overweight and obesity. Among the studies that recruited participants with and without overweight and obesity, the majority of participants were still those with overweight and obesity.

Although there is a paucity of WBI studies among participants with normal weight, WBI is not exclusive to individuals with overweight and obesity. It has been shown to be pervasive across the entire weight spectrum in adults $(15,21)$. In a study of U.S. adults with and without overweight or obesity $(\mathrm{N}=3,504 ; 56.4 \%$ women; $\mathrm{BMI}=28.11 \pm 7.33 \mathrm{~kg} / \mathrm{m} 2)$, higher levels of WBI were experienced by participants with larger BMI's, and those who experienced lower levels of WBI had lower BMI values (15). However, 17.4\% of participants within the high WBI group had normal BMI values (15). Moreover, in a study examining the relationship between WBI and severe eating pathology (binge eating and purging) in a sample of individuals with normal weight $(\mathrm{N}=197 ; 89.3 \%$ women; $\mathrm{BMI}=22.28 \pm 1.89 \mathrm{~kg} / \mathrm{m} 2)$, there was a significant positive relationship between BMI and WBI $(r=0.18, p<0.05)(21)$. 
Despite the fact that WBI has been shown to be more prevalent among women, these results may be due to the fact that many of these studies included sample populations that consisted of primarily female participants; therefore, more research is needed in large samples with an equal distributions of both men and women from multiple weight statuses across the weight spectrum (underweight to obesity).

\subsubsection{Weight Bias Internalization: Health Correlates}

The impacts of experiencing WBI on various health correlates have been summarized by the 2018 systematic review by Pearl and Puhl (12). The researchers identified 74 studies describing the many mental and physical health correlates associated with experiencing WBI. The results of the systematic review highlighted that there were fewer studies examining physical health parameters, such as weight loss and measures of physical activity and the obtained results were less consistent than those obtained for mental health correlates.

For instance, in terms of mental health, WBI has been shown to be associated with symptoms of depression and anxiety $(12,14,22,23)$, low self-esteem (24-26) and reduced quality of life (27-29). In terms of physical health, the systematic review discussed that out of the six studies that assessed the relationship between WBI and weight loss, only one study reported significant findings. In that specific study, the researchers concluded that 12 months after undergoing bariatric surgery, pre-operative WBI scores predicted a lower percentage of weight loss $(\mathrm{B}=-1.41, \mathrm{p}<0.05)$ in a sample of adults with obesity $(\mathrm{N}=170 ; 81.9 \%$ women; pre-operative $\mathrm{BMI}=47.80 \pm 8.30 \mathrm{~kg} / \mathrm{m} 2$ ) (30). Since the publication of the 2018 systematic review, a few studies investigating WBI and health have been published. For instance, in a 14-week low calorie diet lifestyle intervention study conducted among adults with obesity $(\mathrm{N}=133 ; 86.1 \%$ women; baseline $\mathrm{BMI}=40.80 \pm 5.90 \mathrm{~kg} / \mathrm{m} 2$ ), researchers found that WBI scores predicted a reduced likelihood of participants achieving five and ten percent weight loss $(\mathrm{OR}=0.63$ [95\% CI: $0.43,0.90]$ and $\mathrm{OR}=0.66$ [95\% CI: 0.46,0.94], respectively) (31).

Beyond the physical health correlates of WBI, the underlying behavioural correlates are poorly understood. WBI has been shown to be significantly associated with weight cycling (multiple instances of losing and gaining 20 pounds or more) and reduced weight loss 
maintenance (i.e. not capable of maintaining previous intentional weight loss) $(17,32,33)$. The reasons why consistent and effective weight loss is not common among those with WBI is unclear. In particular, the specific behaviours in which these individuals are attempting to control their weight are unknown.

\subsubsection{Weight Bias Internalization \& Weight Control Behaviours}

The literature investigating the relationship between WBI and weight control behaviours has been heavily focused on one's motivation or desire to lose weight $(15,34,35)$. For instance, one study $(\mathrm{N}=46 ; 52.2 \%$ women; $\mathrm{BMI}=30.52 \pm 5.09 \mathrm{~kg} / \mathrm{m} 2)$ concluded that in response to instances of weight stigmatization, WBI was significantly associated with a lower motivation to perform dieting behaviours $(\mathrm{B}=-0.23, \mathrm{p}<0.05)$. This was assessed by participants recording their experiences with weight stigmatization throughout the day and reporting their motivation to perform dieting behaviours whenever those instances occurred (34). The obtained results from this study were consistent with other research linking weight stigmatization with an increased urge to eat (36). However, researchers have also discovered that among adults with high WBI, $94.9 \%$ of participants had attempted to lose weight in the previous year, compared to $71.7 \%$ of participants with low WBI (15). The discrepancy in results between these two studies is likely founded in the differences in study design and sample populations - one was conducted in a small community sample ( $\mathrm{N}=46)(34)$, while the other was conducted in a national sample of U.S. adults $(\mathrm{N}=3,504)(15)$. Moreover, having desires to lose weight does not necessarily translate into actively pursuing weight control or weight loss (37). In a study examining weight stigmatization and health correlates among gym members with overweight and obesity $(\mathrm{N}=389$; $75 \%$ women; $\mathrm{BMI}=32.98 \pm 7.66 \mathrm{~kg} / \mathrm{m} 2$ ), researchers reported that greater WBI was significantly associated with increased “maladaptive coping responses”. 'Maladaptive coping responses' was assessed by eight items which included a variety of unhealthy behaviours such as trying to lose weight quickly, feeling badly about one's weight or eating more food (28). This questionnaire did however lack specificity in investigating precise behaviours that individuals performed in order to control their weight and assessed overarching sentiments that one would perform following an instance of weight stigmatization. Although a significant relationship between WBI 
and the summary measure of 'maladaptive coping responses' was detected, subsequent analyses focused on the specific weight control behaviours did not show any significant results (28). These results only highlight the importance of additional research aimed at investigating the relationship between WBI and weight control behaviours. More specifically, the precise behaviours that individuals perform with the intention to control their weight.

Another weight control behaviour that is often included in WBI research is physical activity. The trend throughout the research points towards a negative relationship between WBI and both the time spent performing physical activity (38) and the weekly frequency of participating in physical activity $(33,39,40)$. For instance, our team also found that mean WBI was negatively associated with the time spent performing moderate and strenuous intensity physical activity $(B=-0.10, p<0.05$ for both relationships) from the same dataset utilized in this thesis (41). However, two other studies showed no significant associations between WBI and the frequency of performing different intensities of physical activity (35) or going to the gym (28). Thus, the relationships between WBI and physical activity measures are inconsistent, highlighting the need to further examine the relationship between WBI and specific healthy weight control behaviours, such as physical activity.

Many of the published research examining the relationship between WBI and weight control behaviours consisted of samples containing either women only, or mostly women $(28,38-40,42)$. Investigating health correlates associated with WBI in male populations is crucial as WBI has been shown to be significantly associated with increased body dissatisfaction $(\mathrm{r}=0.60, \mathrm{p}<0.01)$ and reduced mental and physical quality of life $(\mathrm{r}=-0.36$ and $\mathrm{r}=-0.22, \mathrm{p}<0.01$, respectively) in male university students $(\mathrm{N}=200 ; \mathrm{BMI}=24.12 \pm 4.31 \mathrm{~kg} / \mathrm{m} 2)(43)$. Thus, studies examining and comparing the specific weight control behaviours associated with experiencing WBI are lacking in both men and women.

\subsection{Weight Perception}

WBI has also been shown to be associated with weight perception in adult populations $(15,19,33,44)$. For example, in a sample of U.S. adults with and without obesity $(\mathrm{N}=148 ; 50 \%$ women; $\mathrm{BMI}=27.97 \pm 7.27 \mathrm{~kg} / \mathrm{m} 2$ ), participants who perceived themselves as having obesity had 
significantly higher mean WBI scores compared to any other weight perception group (i.e. underweight, about the right weight and overweight) (19). Moreover, in a sample of U.S. adults with and without obesity $(\mathrm{N}=3,504 ; 56.4 \%$ women; $\mathrm{BMI}=28.11 \pm 7.33 \mathrm{~kg} / \mathrm{m} 2)$, among those with low levels of WBI, 74.3\% perceived themselves to be "about the right weight", while only $19.7 \%$ and $1.3 \%$ perceived themselves as having overweight and obesity, respectively. Among those with high levels of WBI, only $14.3 \%$ of participants perceived themselves to be "about the right weight", while $46 \%$ and $37.3 \%$ perceived themselves as having overweight and obesity, respectively (15). These results demonstrated that as the level of WBI increased, so did the number of participants who perceived themselves as having overweight or obesity. Although individuals may accurately classify their objective weight status by BMI and their subjective weight status by weight perception, there are often instances of misperception (underestimation or overestimation). For instance, in the same study examining a sample of U.S. adults with and without obesity, $19.2 \%$ of participants within the normal BMI range overestimated their weight status, perceiving themselves as having overweight or obesity. Contrarily, $34.7 \%$ and $4.7 \%$ of participants classified as having overweight and obesity based on BMI, underestimated their weight status, respectively (15).

Perceiving one's self as overweight has been demonstrated to be a significant predictor of attempting to lose weight and of performing certain healthy and unhealthy weight control behaviours (45). The majority of the studies in adults examining the relationship between weight perception and weight control behaviours has been heavily focused on weight management outcomes, such as weight loss pursuits and a desire to weigh less. For instance, in a study examining a nationally representative sample of U.S. adults with overweight and obesity $(\mathrm{N}=4,784 ; 46.6 \%$ women; $\mathrm{BMI}=31.3 \mathrm{~kg} / \mathrm{m} 2$ (SE:0.13)), researchers determined that men and women with overweight or obesity who misperceived their weight as being "normal" were $71 \%$ and $65 \%$ less likely to report wanting to lose weight, and $60 \%$ and $56 \%$ less likely to have tried to lose weight in the previous year, respectively, compared to those who accurately perceived themselves as having overweight (46). Moreover, in another nationally representative sample of U.S. adults ( $N=16,720 ; 49.5 \%$ women), compared to those who perceive themselves as having a normal weight, men and women who perceived themselves as overweight had 32 and 67 times higher odds of a desire to weigh less, respectively (37). One study concluded that among young adults aged 18 to 26 with overweight or obesity $(\mathrm{N}=5,184 ; 49.2 \%$ women; men $\mathrm{BMI}=31.3 \mathrm{~kg} / \mathrm{m} 2$ 
$(\mathrm{SE}: 0.34)$; women $\mathrm{BMI}=32.9 \mathrm{~kg} / \mathrm{m} 2(\mathrm{SE}: 0.32))$, those who underestimated their weight status as normal weight, were less likely to perform unhealthy weight control behaviours, such as meal skipping/fasting (men: OR: 0.31, [95\% CI: 0.20-0.48]; women: OR: 0.25, [95\% CI: 0.14-0.43]) and taking diet pills/taking laxatives/diuretics (men: OR: 0.10, [95\% CI: 0.04-0.25]; women: OR: 0.10, [95\% CI: 0.04-0.25]) than those who accurately estimated their weight status (47). In another study examining the relationship between weight perception and weight control behaviours among Korean women ( $\mathrm{N}=8,584 ; 56 \%$ normal weight BMI), those with overweight who overestimated their weight status as having obesity had an increased likelihood of fasting/skipping meals and taking diet pills for weight control (OR: 5.72, [95\% CI: 2.45-13.56] and OR: 3.26, [95\% CI: 1.15-8.23], respectively) (48). However, very few studies have examined the association between weight perception and specific weight control behaviours in adults. Instead, this relationship has been more thoroughly examined in adolescent populations. This is likely due to the fact that body image concerns and associated dangerous eating behaviours are highly prevalent among adolescents (49) and that younger individuals are more likely than older individuals to be motivated to lose weight for physical appearance or social reasons, rather than health reasons (50). For instance, in samples of adolescents aged 11 to 18 years old, those who overestimated their weight also had an increased likelihood of engaging in unhealthy weight control behaviours such as, caloric restriction, diet pill and laxative consumption and reductions in both physical activity and fruit consumption, compared to accurate estimators (51-56). These results demonstrate that adolescents who overestimated their weight status were more likely to perform unhealthy behaviours for the purpose of weight control.

Weight status misperception appears to occur in both men and women across the entire BMI spectrum. However, the prevalence of underestimation and overestimation significantly varies between sexes: men are significantly more likely to either accurately estimate or underestimate their weight, while women are significantly more likely to overestimate their weight (37,57-61). For example, in a study by Lemon et al., among participants within the normal range of $\mathrm{BMI}(\mathrm{N}=899 ; 79 \%$ women; 33\% with normal weight; 32.1\% with overweight; $34.8 \%$ with obesity), $26.8 \%$ of men perceived themselves to be underweight, compared to only $6 \%$ of women. Moreover, within the same group of individuals within the normal BMI range, $55.2 \%$ of women overestimated their weight as slightly or moderately overweight, compared to 
only $22.7 \%$ of men (61). Weight status misperception has also been measured in samples of individuals with normal weight measured by BMI $(\mathrm{N}=197 ; 89.3 \%$ women; $\mathrm{BMI}=22.28 \pm 1.89$ $\mathrm{kg} / \mathrm{m} 2$ ), where $38 \%$ of participants subjectively reported their current weight to be overweight or obese (21).

Despite the fact that the relationship between weight misperception and specific weight control behaviours has been thoroughly examined in samples of adolescents, more research is needed to understand this relationship among adults in order to better comprehend if the established relationship among adolescents translates and continues to be present as men and women age. This could provide information on whether informing an adult patient of their weight status is detrimental or advantageous to one's weight management strategies (45). Additionally, it could aid in better understanding some of the primary reasons for adults performing unhealthy and extreme weight control behaviours.

\subsection{Objectives}

To address these gaps in the literature, this thesis aims to assess:

1) The relationship between WBI and health and unhealthy weight control behaviours;

2) The relationship between weight perception (underestimation, overestimation and accurate estimation) and healthy and unhealthy weight control behaviours and;

3) Whether these relationships differ between men and women. 


\subsection{Hypotheses}

We hypothesize the following:

1) WBI will be negatively associated with the number of healthy weight control behaviours and positively associated with the number of unhealthy and extreme weight control behaviours.

2) Weight underestimation will be positively associated with the number of healthy weight control behaviours, but negatively associated with the number of unhealthy and extreme behaviours. Weight overestimation will be negatively associated with the number of healthy weight control behaviours, but positively associated with the number of unhealthy and extreme weight control behaviours.

3) WBI scores and weight overestimation will be higher among women compared to men, and weight underestimation and accurate estimation will be higher among men compared to women. Additionally, women will perform more weight control behaviours (healthy, unhealthy and extreme) compared to men. 


\section{CHAPTER 2: METHODS}

\subsection{Participants}

Data were collected as part of the Compensatory Health Behaviour Study at Concordia University's PERFORM Centre in Montreal, Quebec. The aim of that study was to gather information regarding the performance of certain health behaviours, as well as attitudes and beliefs regarding general health in a Canadian sample of adults from three objectively measured (based on BMI) weight statuses (normal weight, overweight and obesity). Once recruitment in one of the three weight statuses reached approximately 65 participants, the recruitment for that specific weight status was closed. This ensured an equal distribution of participants between weight statuses. A convenience sample of adults were recruited to participate in the study via flyers, e-mails and word-of-mouth $(n=175)$. This study entailed a one-time in-person assessment. Exclusion criteria for this study included being pregnant, recently given birth (within eight weeks) or currently nursing, being categorized as underweight (BMI <18.5), being less than 18 years of age, or having an implanted electronic device (e.g. pacemaker). Thirteen participants were excluded due to missing or unreliable data based on inconsistencies in responses or comments made by the research team regarding the credibility of the responses of certain participants. One participant had a BMI below $18.5 \mathrm{~kg} / \mathrm{m} 2$, resulting in a final analytic sample of 161 participants. All participants provided informed consent and were given a \$25 gift card as compensation for their time. The research ethics committee of the ministry of health and social services approved this study.

\subsection{Measures}

\section{Weight Bias Internalization}

The Weight Bias Internalization Scale (WBIS), an eleven-item questionnaire, was utilized to measure the extent to which individuals value themselves based on their weight status. Items were assessed on a five-point Likert scale, ranging from "strongly disagree" to "strongly agree". An example of one of these items is "I don't feel that I deserve to have a fulfilling social life, because of my weight" (see Appendix page 66 for 
complete questionnaire). Two of the items were reverse coded in order to ensure that higher scores were indicative of more severe WBI. The mean WBI was utilized in analyses as recommended in the literature (14). Within our sample, the WBIS had high internal consistency (Cronbach's $\alpha=0.92$ ).

\section{Healthy Weight Control Behaviours}

The performance of healthy weight control behaviours was assessed by asking participants the following question: "How often have you done each of the following things in order to lose weight or avoid gaining weight during the past year?"(62). Items included performed exercise, ate more fruits and vegetables, ate fewer high-fat foods, ate fewer sweets, drank less soda pop (not including diet pop) and watched portion/serving sizes (see Appendix page 67 for the complete questionnaire). Items were evaluated on a four-point scale, providing participants with the following options: "never", "rarely", "sometimes" or "often". In accordance with the literature, "never" and "rarely" were combined, indicating that the participant did not perform a specific behaviour, while "sometimes" and "often" were combined, indicating that the participants did in fact perform a specific behaviour (62). Within this sample, the questionnaire had relatively high internal consistency for the "never/rarely" versus "sometimes/option" methodology (Cronbach's $\alpha=0.79$ ).

For this study, healthy weight control behaviours, were further categorized into either additive or restrictive healthy weight control behaviours. Additive behaviours were those that had to be implemented as part of an individual's lifestyle (e.g., performing exercise and consuming more fruits and vegetables), while the restrictive behaviours were those that had to be removed from an individual's lifestyle (e.g., consuming fewer high-fat foods, fewer sweets, drinking less soda pop and watching portion sizes) in order to improve one's health. As this organization had not been previously conducted by other researchers, the implications of this analytic decision are described in the discussion.

In order to calculate the total number of healthy weight control behaviours performed, the number of behaviours that received a "sometimes" or "often" response was summated. The same protocol was established for the additive and restrictive healthy weight control behaviours. This is a variation to what a previous study conducted, where 
researchers only reported whether or not at least one of the healthy weight control behaviours were performed (62). Instead of obtaining data on whether or not at least one of the healthy weight control behaviours were performed, we decided it would be beneficial to understand how many of these specific behaviours were being performed.

\section{Unhealthy \& Extreme Weight Control Behaviours}

The use of unhealthy and extreme weight control behaviours was assessed by asking participants the following question: "Have you done any of the following things in order to lose or avoid gaining weight during the past year?" (62). Response options were "yes" or "no" for each item. Items included both unhealthy and extreme weight control behaviours. Unhealthy items included fasting, eating very little food, using food substitutes (powders or special drinks), skipping meals and smoking more cigarettes. Extreme items included taking diet pills, forcing one's self to vomit, using laxatives and using diuretics (see Appendix page 67 for the complete questionnaire). For this study, "smoking more cigarettes" was eliminated from the analysis due to the fact that it assumed that the individual was already a cigarette smoker. In this sample, this questionnaire had moderate internal consistency for unhealthy/extreme behaviours (Cronbach's $\alpha=0.58$ ).

In order to calculate unhealthy weight control behaviours, the number of behaviours that were performed were added together to obtain subtotals of unhealthy, or extreme weight control behaviours, as well as their combined total. The same protocol to tabulate the healthy weight control behaviours as previously described was utilized for the unhealthy and extreme weight control behaviours.

\section{BMI}

Height and weight were measured in duplicate by trained research assistants to the nearest $\mathrm{cm}$ or $\mathrm{kg}$, respectively. The following objectively measured BMI classifications were used, according to the National Institute of Health: underweight $(<18.5 \mathrm{~kg} / \mathrm{m} 2)$, normal weight $\left(18.5 \mathrm{~kg} / \mathrm{m}_{2}-24.9 \mathrm{~kg} / \mathrm{m} 2\right)$, overweight $(25 \mathrm{~kg} / \mathrm{m} 2-29.9 \mathrm{~kg} / \mathrm{m} 2)$ and obesity $(>30 \mathrm{~kg} / \mathrm{m} 2)(63)$. 


\section{Perceived Weight Status}

Participants were asked to complete the following statement, "At this time, do you feel that you are (blank)". Response options included: "very underweight", "somewhat underweight", "about the right weight", "somewhat overweight" or "very overweight". This subjective response was then compared to the participants' weight status based on objectively measured BMI in order to identify whether the participant accurately perceived their weight, or whether there were discrepancies (underestimations and overestimations) between subjective and objective measurements. Weight status discrepancies between subjective perceptions and objective measurements were identified as follows:

Weight underestimation: participants who subjectively identified themselves as having a weight status below their objectively measured weight status. For example, if a participant perceived themselves as being "about the right weight", but their objective BMI classified them as having overweight or obesity, this was considered as underestimation. Moreover, if a participant perceived themselves as being "somewhat overweight" but their BMI was above $30 \mathrm{~kg} / \mathrm{m} 2$, indicating that this person was living with obesity, this was also classified as weight underestimation.

Weight overestimation: participants who subjectively identified themselves as having a weight status greater than their objectively measured weight status. For example, if a participant perceived themselves as being overweight (somewhat or very overweight), but their objectively measured BMI classified them as having a "normal weight", this was considered weight status overestimation.

Accurate estimation: participants who displayed no discrepancies between one's subjective and objective weight status.

\section{Demographic Questionnaire}

The demographic questionnaire included items assessing age, sex, and race. 


\subsection{Statistical Analysis}

Statistical analyses were conducted using IBM SPSS Statistics 24. Descriptive characteristics were analysed with t-tests and chi-square to determine sex differences with continuous and categorical variables, respectively. To address the primary objective of this study, multiple linear regressions were utilised in order to assess the relationship between mean WBI and the total number of weight control behaviours. The assumptions needed to utilise a linear regression (linearity, homoscedasticity and independence) were met when examining the relationship between mean WBI and the total number of healthy and unhealthy weight control behaviours. However, these assumptions were not met upon examining the total number of extreme weight control behaviours performed. Therefore, a logistic regression was performed to determine the relationship between mean WBI and the likelihood of performing at least one extreme weight control behaviour. Additionally, multiple logistic regressions were performed to determine the relationship between mean WBI and the likelihood of performing any specific weight control behaviour. All regression models were adjusted for age, sex, race (White Caucasian versus non-Caucasian) and weight status perception (overestimation vs. accurate estimation, underestimation vs. accurate estimation).

To address the secondary objective of this study, weight status perception was additionally included in the aforementioned regression models to address whether discrepancies between one's subjective and objective weight status were independently associated with weight control behaviours. Weight overestimation and weight underestimation were separate covariates in the model, with accurate weight estimation as the reference group.

To address the third objective of this study, all regressions were additionally stratified by sex to determine whether these relationships differed between men and women. Prior to conducting any analyses stratified by sex, significant interaction effects were detected for each analysis. 


\subsection{Sensitivity Analysis}

A subsequent sensitivity analysis was performed, whereby the participants with BMI values within $1 \mathrm{~kg} / \mathrm{m} 2$ of the BMI classification cut-off values were eliminated $(n=48)$. BMI is a crude measurement and limitations have been reported in accurately assessing aspects such as adiposity (64). Eliminating those who had BMI values within $1 \mathrm{~kg} / \mathrm{m} 2$ of each BMI classification cut-off was performed in order to reduce misclassification of those within each weight perception category. For example, if an individual had a BMI of $25.1 \mathrm{~kg} / \mathrm{m} 2$ (classified as overweight by BMI standards), but perceived themselves as having normal weight, this would be considered weight underestimation. However, that individual's BMI may not correctly represent someone who is categorized as overweight based on greater adiposity as this individual's weight and BMI may be elevated due to greater muscle mass. Therefore, eliminating those within 1 $\mathrm{kg} / \mathrm{m} 2$ of the cut-offs may reduce the misclassification within each weight perception group and be able to better detect discrepancies between one's objective and subjective weight status. 


\section{CHAPTER 3: RESULTS}

\section{Manuscript Title: The Relationship between Weight Bias Internalization and Healthy and Unhealthy Weight Control Behaviours}

Manuscript formatted for Obesity Facts. This manuscript was submitted for consideration for publication on June 1st, 2020 and is currently under review.

Matthew Levy, BSc1, Lisa Kakinami, $\mathrm{PhD}_{2,3}$, and Angela S. Alberga, $\mathrm{PhD}_{1}$

1 Department of Health, Kinesiology and Applied Physiology, Concordia University 7141 Sherbrooke St West, SP 165.31

Montreal, QC, Canada H4B 1R6

2 Department of Mathematics and Statistics, Concordia University, Montreal, Quebec, Canada 1455 Boulevard de Maisonneuve West

Montreal, QC, Canada H3G 1M8

3 PERFORM Centre, Concordia University

7200 Sherbrooke St West

Montreal, QC, Canada H4B 1R6

Short Title: Weight Bias Internalization and Weight Control Behaviours

Corresponding author:

Angela S. Alberga, PhD

Assistant Professor, Department of Health, Kinesiology, and Applied Physiology, Concordia University

Adjunct Professor, Department of Pediatrics, Faculty of Medicine, McGill University

Concordia University

7141 Sherbrooke St West

Montreal, Quebec, Canada

H4B 1R6

Phone: (514) 848-2424 ext. 3371

Email: angela.alberga@concordia.ca

Number of Tables: 5

Word Count: 3263 words

Keywords: Weight bias internalization, weight bias, weight perception, weight control behaviours, weight status 


\begin{abstract}
Introduction: Weight bias internalization (WBI) is associated with disordered eating symptomology and motivation to control weight. The relationship between WBI and specific weight control behaviours and how these behaviours differ between men and women is not well understood. The objectives of this study are to determine (1) the relationship between WBI and weight control behaviours, (2) whether weight perception is independently associated with weight control behaviours and (3) whether these relationships differ between sexes.

Methods: Canadian adults $(\mathrm{N}=161 ; 52.8 \%$ female; $\mathrm{BMI}=26.5 \pm 4.99 \mathrm{~kg} / \mathrm{m} 2)$ completed questionnaires pertaining to WBI, weight control behaviours (healthy, unhealthy, extreme) and weight perception (accurate, under-, or over-estimation compared with objectively measured body mass index). The cross-sectional relationship between (1) WBI or (2) weight perception with the total number of healthy and unhealthy or extreme weight control behaviours, and likelihood of performing specific weight control behaviours were assessed with linear, and logistic regression models respectively. All analyses were conducted adjusting for age, sex, and race. Subsequent analyses were stratified by sex.
\end{abstract}

Results: WBI was associated with an increased likelihood of performing exercise for weight control $(\mathrm{OR}=2.20, \mathrm{p}<0.05)$; increased likelihood of skipping meals in women $(\mathrm{OR}=2.51$, $\mathrm{p}<0.01)$, and consuming little amounts of food in men $(\mathrm{OR}=2.33, \mathrm{p}<0.01)$. Weight perception was not associated with weight control behaviours.

Conclusions: WBI was associated with various weight control behaviours. This study highlights the importance of assessing WBI in clinical practice with patients seeking to manage their weight. Future longitudinal research should be conducted to further understand the behavioural and health effects from WBI. 


\section{Introduction}

Negative attitudes and beliefs toward individuals with overweight or obesity (weight bias) has become increasingly prevalent, and has not been as widely contested as other forms of bias and discrimination [1]. Research has demonstrated several negative mental health and behavioural correlates associated with experiencing weight bias, such as depression, anxiety, eating disturbances [2], as well as future weight gain [3]. This growing interest in examining weight bias and its effects has led to the conceptualization and further investigation of self-directed stigma known as 'weight bias internalization' (WBI). WBI occurs when an individual is: (1) made aware of the negative stereotypes that are held throughout society; (2) believes them to be true; and then (3) internalizes these attitudes to the detriment of their confidence in their own capabilities or social adequacy $[4,5]$. People with greater WBI have poorer mental health, including greater anxiety, depression, and lower self-esteem and quality of life [6]. Although sex differences in WBI have not been thoroughly investigated, a study conducted among individuals with overweight who also had binge eating disorder, determined that mean WBI scores were significantly higher among women compared to men [7].

Previous research has linked WBI to physical aspects such as reduced physical health-related quality of life, increased body mass index (BMI) and lower physical activity participation [6]. These studies primarily consisted of individuals with overweight or obesity. However, WBI can still be present among adults with normal body weight $[6,8]$ but research is limited. Thus, it is vital to include participants across the entire spectrum of BMI when examining WBI and physical health. As WBI has mental and physical health correlates, more research is needed to examine the relationship between WBI and health behaviours, such as weight control practices. However, only one previous study investigated whether WBI is associated with weight control 
behaviours. No significant associations were detected [9]. Although research has also suggested that a relationship exists between WBI and subjective weight status [10], whether weight perception is independently associated with weight control behaviours after statistically adjusting for WBI is unknown. These relationships are especially important to examine in both men and women in order to establish targeted weight bias and WBI reduction initiatives in the future. Thus, the objectives of this study were to: (1) examine the relationship between WBI and healthy and unhealthy weight control behaviours; (2) examine the relationships between weight perception and weight control behaviours; and (3) determine if these relationships differed between men and women.

\section{Materials \& Methods}

\section{Procedure \& Participants}

A convenience sample of adults were recruited to participate in the study via flyers, e-mails and word-of-mouth ( $\mathrm{n}=175)$. Exclusion criteria for this study included being pregnant, recently given birth (within eight weeks) or currently nursing, being categorized as underweight (BMI $<18.5$ ), being less than 18 years of age, or having an implanted electronic device (e.g. pacemaker). Thirteen participants were excluded due to missing or unreliable data. One participant had a BMI below $18.5 \mathrm{~kg} / \mathrm{m} 2$, resulting in a final analytic sample of 161 participants. Study participation entailed a one-time in-person assessment at Concordia University's PERFORM Centre (a research centre focused on health promotion and disease prevention) in Montreal, Quebec. All participants provided written informed consent and were given a \$25 gift card as compensation for their time. This study was conducted ethically in accordance with the World Medical 
Association Declaration of Helsinki and was approved by the research ethics committee of the ministry of health and social services (reference number CCER 17-18-01).

\section{Measures}

Trained research assistants measured the participants' height and weight (to the nearest $\mathrm{cm}$ or $\mathrm{kg}$, respectively) in duplicate. The average of the two measures were used to compute BMI. Weight status was categorized as normal weight (18.5-24.99 kg/m2), overweight $(25.0-29.99 \mathrm{~kg} / \mathrm{m} 2)$ or having obesity $(>30.0 \mathrm{~kg} / \mathrm{m} 2)$. Participants also completed the following questionnaires:

Weight Bias Internalization Scale (WBIS; Durso \& Latner, 2008) is an eleven-item measure which assessed the extent to which an individual values themselves based on their weight status [11]. Items (such as: "I don't feel that I deserve to have a really fulfilling social life, because of my weight") were assessed on a five-point Likert scale (strongly disagree to strongly agree). Two items were reverse coded in order to ensure that higher scores were indicative of more severe WBI. The mean WBIS score was calculated. Within this sample, the WBIS had high internal consistency (Cronbach's $\alpha=0.92)$.

Healthy Weight Control Behaviours (Neumark-Sztainer et al., 2012) is a six-item measure which is assessed by asking participants the following question: "How often have you done each of the following things in order to lose weight or avoid gaining weight during the past year?" [12].

Items were evaluated on a four-point Likert scale, providing participants with the following options: "never", "rarely", "sometimes" or "often". Items included performed exercise, ate more fruits and vegetables, ate fewer high-fat foods, ate fewer sweets, drank less soda pop (not including diet pop) and watched portion/serving sizes. The test-retest agreement of never/rarely versus sometimes/often has been shown to be $88 \%$ (14). Thus, in accordance with the literature, 
response categories "never" and "rarely" were combined, and "sometimes" and "often" were combined [12] (Cronbach's $\alpha=0.79$ in this study).

Healthy weight control behaviours were further categorized into additive or restrictive weight control behaviours. Additive behaviours were those that had to be implemented as part of an individual's lifestyle (e.g., performing exercise and consuming more fruits and vegetables), while the restrictive behaviours (e.g., consuming fewer high-fat foods, fewer sweets, drinking less soda pop and watching portion sizes) are those that had to be removed from an individual's lifestyle in order to improve one's health. The number of behaviours were added together to obtain a subtotal of healthy weight control behaviours performed, as well as subtotals for additive and restrictive healthy weight control behaviours.

Unhealthy \& Extreme Weight Control Behaviours (Neumark-Sztainer et al., 2012) is a nine-item measure which is assessed by asking participants the following question: "Have you done any of the following things in order to lose weight or avoid gaining weight during the past year?" [12] (response options: "yes" or "no" for each item). Unhealthy items included fasting, eating very little food, using food substitutes (powders or special drinks), skipping meals and smoking more cigarettes. Extreme items included taking diet pills, forcing one's self to vomit, using laxatives and using diuretics. For this study, "smoking more cigarettes" was eliminated from the analysis due to the fact that it assumed that the individual was already a cigarette smoker. In this sample, this questionnaire had moderate internal consistency for unhealthy/extreme behaviours (Cronbach's $\alpha=0.58$ ). The number of behaviours that were performed were added together to obtain subtotals of unhealthy, or extreme weight control behaviours, as well as their combined total. 
Perceived Weight Status. Participants were asked to complete the following statement, "At this time, do you feel that you are (blank)". Response options included: "very underweight", "somewhat underweight", "about the right weight", "somewhat overweight" or "very overweight". This response was then compared to weight status based on objectively measured BMI in order to identify whether the participant accurately perceived their weight, or whether there were discrepancies (underestimations and overestimations) between perceptions and objective measurements. For instance, if a participant perceived themselves as being "about the right weight", but their objective BMI classified them as having overweight or obesity, this would be an example of underestimation. Moreover, if a participant perceived himself or herself as being "somewhat overweight" but their BMI was above $30 \mathrm{~kg} / \mathrm{m} 2$, indicating that this was an individual with obesity, this would also be classified as weight underestimation. On the other hand, if a participant's objectively measured BMI classified them as being of "normal weight", but they felt as though they had overweight (somewhat or very overweight), this was considered weight status overestimation. If there were no discrepancies between one's subjective and objective weight status, this was considered accurate estimation. Moreover, a subsequent sensitivity analysis was performed whereby participants with BMI values within $1 \mathrm{~kg} / \mathrm{m} 2$ of the BMI classification values were removed and were re-analysed. As results were unaffected by the implementation of the sensitivity analysis, results for the entire sample population are presented.

\section{Data Analysis}

All analyses were conducted using IBM SPSS Statistics 24. Descriptive characteristics were analysed with t-tests and chi-square to determine sex differences. To assess the primary objective, multiple linear regressions were performed in order to determine the relationship between mean WBI and the (1) total number of healthy and the (2) total of unhealthy and 
extreme weight control behaviours. Linear regression assumptions were met for these outcomes but were not met for the total number of extreme weight control behaviours. Therefore, a logistic regression was performed to determine the relationship between mean WBI and the likelihood of performing at least one extreme weight control behaviour. Additionally, multiple logistic regressions were performed in order to determine the relationship between mean WBI and the likelihood of performing any specific weight control behaviour. All regression models were adjusted for age, sex, race (Caucasian versus non-Caucasian) and weight status discrepancy (overestimation vs. accurate estimation, underestimation vs. accurate estimation). Adjusting for weight status discrepancy in the regression models also fulfilled the secondary objective (whether discrepancies between one's subjective and objective weight status may be independently associated with weight control behaviours). Weight overestimation and weight underestimation were separate covariates in the model, with accurate weight estimation as the reference group. The tertiary objective (whether these relationships differed between men and women) was assessed by stratifying regression models by sex.

\section{Results}

The total sample consisted of a nearly equal distribution of men and women, with $52.8 \%$ of the population being female (Table 1). The mean BMI among women was significantly higher compared to men (27.38 vs. $25.50 \mathrm{~kg} / \mathrm{m} 2, \mathrm{p}=0.02)$. Mean WBI score was higher among women compared to men, although the difference was not statistically significant (2.30 vs. $2.05, \mathrm{p}=0.09)$. Discrepancy between weight perception and weight status significantly differed between women and men $(p=0.03)$. There were no significant differences between men and women in the mean number of healthy or unhealthy weight control behaviours performed. However, the mean 
number of extreme weight control behaviours was significantly higher in women compared to men (0.19 vs. $0.03, \mathrm{p}<0.0001)$.

\section{WBI and Healthy Weight Control Behaviours}

After adjusting for covariates, mean WBI was not significantly associated with the total number of healthy weight control behaviours in linear regression models in either men or women (Table 2). However, for every unit increase in mean WBI, the total number of additive healthy weight control behaviours significantly increased within the full sample $(B=0.11, p<0.05)$ and among women $(\mathrm{B}=0.13, \mathrm{p}<0.05)$. When examining the relationship between mean WBI and the likelihood of utilizing specific healthy weight control behaviours from multiple logistic regression, mean WBI was significantly associated with an increased likelihood of performing exercise for weight control, within the full sample $(\mathrm{OR}=2.20,[95 \% \mathrm{CI}: 1.05,4.64], \mathrm{p}<0.05$, Table 3). Mean WBI was not associated with any specific healthy weight control behaviours upon stratifying by sex.

\section{WBI and Unhealthy or Extreme Weight Control Behaviours}

In contrast, for every unit increase in mean WBI, the total number of combined unhealthy and extreme weight control behaviours significantly increased in both women and men $(B=0.55$ and $\mathrm{B}=0.45, \mathrm{p}<0.01$, respectively, Table 4). Results were consistent when examining the relationship between mean WBI and the total number of unhealthy weight control behaviours in both women and men $(B=0.39, p<0.01$ and $B=0.40, p<0.05$, respectively, Table 4$)$. In terms of the extreme weight control behaviours, mean WBI was significantly associated with an increased likelihood of performing at least one extreme behaviour within the entire sample and among women $(\mathrm{OR}=2.66$ [95\% CI: 1.33, 5.33], $\mathrm{p}<0.01$ and $\mathrm{OR}=2.34$ [95\% CI: 1.13, 4.83], $\mathrm{p}<0.05$, respectively, 
Table 4). For specific unhealthy weight control behaviours, mean WBI was significantly associated with an increased likelihood of consuming food substitutes within the entire sample population $(\mathrm{OR}=1.66$ [95\% CI: 1.06, 2.59], $\mathrm{p}<0.05$, Table 5)]. When stratifying by sex, mean WBI was significantly associated with an increased likelihood of skipping meals in women $(\mathrm{OR}=2.51$ [95\% CI: 1.37, 4.60], $\mathrm{p}<0.01$, Table 5), and an increased likelihood of consuming little amounts of food in men $(\mathrm{OR}=2.33$, [95\% CI: 1.24, 4.38], $\mathrm{p}<0.01$, Table 5). The relationship between WBI and specific extreme weight control behaviours were not analysed due to too few cases $(n=18)$.

Weight perception and weight control behaviours

Weight perception discrepancy was not significantly associated with any of the total number of weight control behaviours in the full sample, nor when stratified by sex. Moreover, weight perception discrepancy was not significantly associated with the use of any individual specific healthy, unhealthy or extreme weight control behaviours in the full sample, nor when stratified by sex.

\section{Discussion}

This study demonstrated that WBI was significantly associated with the number of additive healthy weight control behaviours performed, but more specifically, performing exercise for weight control in the full sample. This study also demonstrated that WBI was significantly associated with the total number of unhealthy weight control behaviours, as well as the combination of unhealthy and extreme weight control behaviours performed in the full sample. Since the current study had approximately an equal distribution of men and women, it was possible to determine whether relationships differed by sex. Study results suggest that WBI was 
significantly associated with weight control behaviours among both women and men, but the specific behaviours differed by sex. For instance, WBI was significantly associated with the combined total of unhealthy and extreme weight control behaviours among both women and men, but only an increased likelihood of performing at least one extreme weight control behaviour among women. The results obtained in this current study support previous findings that extreme weight control behaviours are more common among women compared to men [1316]. It has been shown that women are generally more likely than their male counterparts to partake in unhealthy or extreme weight control behaviours due to the sociocultural ideals surrounding beauty and thinness $[17,18]$. Research has also shown that women generally experience more frequent episodes of weight stigmatization compared to males [19]. It has been suggested that experiencing weight stigma and fearing being devalued may increase one's motivation to escape weight stigma by engaging in unhealthy or disordered eating behaviours [20]. Therefore, due to elevated levels of weight stigmatization experienced among women compared to men, the added pressure to achieve thinness as well as an increased motivation to escape the fear of being devalued or stigmatized, might explain elevated levels of WBI among women and the development of unhealthy and extreme weight control behaviours [21]. The secondary objective of this study was to determine how one's perceived weight status might additionally be associated with weight control behaviours in this model. However, neither overestimation nor underestimation was associated with any of the weight control behaviours. It is possible that the lack of significant results is due to the study's relatively small sample size. The number of individuals who were categorized as having inaccurate weight perceptions (either underestimation or overestimation) was relatively small compared with the accurate weight perception group. In order to counter this limitation, weight perception could have been 
classified as accurate perception or non-accurate perception (combining both over- and underestimation into a single group). However, this would not describe the full scope of weight perception and would bias results toward the null.

The literature also suggests discrepant sex differences in risk factors and motivations for performing unhealthy or extreme weight control behaviours [22]. In particular, the motives rooted behind male disordered eating are often different than the thinness-oriented behaviours experienced among women. Disordered eating and the associated behaviours in male populations are more focused on muscularity-oriented behaviours [22] and are often vastly overlooked and understudied $[23,24]$. Additionally, the constructs utilized to assess disordered eating are often focused on behaviours that are more likely to be performed among women to achieve thinness, rather than some of the eating behaviours that are more commonly performed among men, such as drastically increasing protein consumption [25]. It is therefore possible that the lack of significant results could be due to the combination of a small sample, and behaviour measures that despite being well-established, may elicit gendered responses. Therefore, more research is needed to better understand WBI, weight control behaviours and weight perception in both men and women in order to clarify some of the varying motivations that are associated with undertaking unhealthy weight control practices.

\section{Strengths \& Limitations}

This was the first known study to demonstrate a relationship between WBI and specific weight control behaviours. Previous studies reported no significant relationships between WBI and weight control behaviours. Importantly, this study was conducted in a sample of individuals across the BMI spectrum (normal weight, overweight and obesity), allowing for a greater 
comprehension of these relationships. In contrast, the majority of similar previous WBI studies were conducted exclusively among individuals with overweight or obesity [9,10,26,27].

This current study was able to extend the previous research by identifying the precise behaviours that individuals with higher WBI perform in order to control their weight. Previous research was heavily focused on motivation to diet, rather than focusing on the specific diet-related behaviours and were inconsistent $[10,28]$. For example, while one study concluded that adults with higher levels of WBI were significantly more likely to report dieting in the past year [10], another study concluded that higher WBI was negatively associated with a motivation to diet [28]. It is possible that the discrepancy can be attributed to the fact that there may be a distinct difference between having a motivation to undergo weight loss behaviours, and actually implementing these behaviours as part of one's life. Moreover, these previous studies utilized self-reported anthropometric data, unlike this current study where weight and height were objectively measured.

While this study contributed novel findings regarding the relationship between WBI and specific weight control behaviours, certain limitations should be noted. Firstly, considering that this study was cross-sectional by nature, neither causality nor directionality can be inferred. Future longitudinal research should be performed to solidify the results obtained in this current study and to determine how these relationships change over time. Secondly, BMI is a continuous variable and converting it to different weight classifications may introduce misclassification bias. However, BMI classifications are commonly used in the literature [29]. As removing participants within $1 \mathrm{~kg} / \mathrm{m} 2$ of weight status categories did not affect results, the impact of misclassification on our results was likely minimal. Lastly, since the sample size of this study was relatively small, the number of participants who actually performed the specific extreme weight control 
behaviours was insufficient for some analyses. Cronbach's alpha was also relatively low for these unhealthy and extreme weight control behaviours. Therefore, interpretations of some of these estimates should be made with caution. Participants were from a convenience sample and results cannot be generalized to the larger population. Future research should focus on examining this research question in a larger, nationally representative sample of adults.

\section{Conclusion}

In conclusion, mean WBI was significantly associated with a greater likelihood of eating little amounts of food, taking food substitutes and skipping meals. However, these relationships differed by sex. The results of this study emphasize the potential ramifications associated with experiencing WBI on the unhealthy manners in which individuals attempt to control their weight. Results from this study highlight the importance of measuring WBI in future research aimed at investigating weight bias, weight perception and weight control behaviours and to continue to do so in samples of both sexes. Continuing to conduct research in this field will improve our understanding of the impact of WBI, with the hopes of creating and implementing protocols to reduce weight bias and weight bias internalization.

Funding Sources: Matthew Levy greatly acknowledges the Concordia University Merit Scholarship Award. This research was supported by start-up funds from the PERFORM Centre, and a team seed grant from the Office of the Vice President, Research and Graduate Studies from Concordia University. The PERFORM Centre and Concordia University were not involved in the study design, collection, analysis, or interpretation of data, writing the manuscript, or the 
decision to submit the paper for publication. Drs. Kakinami and Alberga gratefully acknowledge les Fonds de Recherche du Québec- Santé for their Chercheur Boursier Awards.

Ethical Statement: This study was conducted ethically in accordance with the World Medical Association Declaration of Helsinki and all participants provided written informed consent. This study was approved by the research ethics committee of the ministry of health and social services (reference number CCER 17-18-01).

Disclosure Statement: The authors declare no conflict of interest.

Author Contributions: All authors conceived the research question. ML drafted the first version of the manuscript and conducted the statistical analysis. LK and ASA were responsible for study design, assisted with data analysis and interpretation of the findings. All authors contributed writing, editing and approval of the final draft submitted. 


\section{References}

1. Savoy S, Boxer P. The impact of weight-biased media on weight attitudes, self-attitudes, and weight-biased behavior. Psychology of Popular Media. 2020;9(1):31-44.

2. Wu Y-K, Berry DC. Impact of weight stigma on physiological and psychological health outcomes for overweight and obese adults: A systematic review. J Adv Nurs. 2018 May;74(5):1030-42.

3. Jackson SE, Beeken RJ, Wardle J. Perceived weight discrimination and changes in weight, waist circumference, and weight status. Obesity (Silver Spring). 2014 Dec;22(12):2485-8.

4. Corrigan P, Watson A, Barr L. The Self-Stigma of Mental Illness: Implications for SelfEsteem and Self-Efficacy. Journal of Social and Clinical Psychology - J SOC CLIN PSYCHOL. 2006 Oct 1;25:875-84.

5. Han S, Agostini G, Brewis AA, Wutich A. Avoiding exercise mediates the effects of internalized and experienced weight stigma on physical activity in the years following bariatric surgery. BMC Obesity. 2018 Jul 2;5(1):18.

6. Pearl RL, Puhl RM. Weight bias internalization and health: a systematic review. Obes Rev. 2018;19(8):1141-63.

7. Pearl RL, White MA, Grilo CM. Weight bias internalization, depression, and self-reported health among overweight binge eating disorder patients. Obesity (Silver Spring). 2014 May;22(5):E142-148.

8. Schvey NA, White MA. The internalization of weight bias is associated with severe eating pathology among lean individuals. Eat Behav. 2015 Apr;17:1-5.

9. Schvey NA, Sbrocco T, Bakalar JL, Ress R, Barmine M, Gorlick J, et al. The experience of weight stigma among gym members with overweight and obesity. Stigma and Health. 2017;2(4):292-306.

10. Puhl RM, Himmelstein MS, Quinn DM. Internalizing Weight Stigma: Prevalence and Sociodemographic Considerations in US Adults. Obesity (Silver Spring). 2018;26(1):16775 .

11. Durso LE, Latner JD. Understanding self-directed stigma: development of the weight bias internalization scale. Obesity (Silver Spring). 2008 Nov;16 Suppl 2:S80-86.

12. Neumark-Sztainer D, Wall MM, Larson N, Story M, Fulkerson JA, Eisenberg ME, et al. Secular trends in weight status and weight-related attitudes and behaviors in adolescents from 1999 to 2010. Prev Med. 2012 Jan;54(1):77-81.

13. Neumark-Sztainer D, Rock CL, Thornquist MD, Cheskin LJ, Neuhouser ML, Barnett MJ. Weight-control behaviors among adults and adolescents: associations with dietary intake. Prev Med. 2000 May;30(5):381-91. 
14. Neumark-Sztainer D, Story M, Hannan PJ, Perry CL, Irving LM. Weight-related concerns and behaviors among overweight and nonoverweight adolescents: implications for preventing weight-related disorders. Arch Pediatr Adolesc Med. 2002 Feb;156(2):171-8.

15. Kim Y, Austin SB, Subramanian SV, Kawachi I. Body weight perception, disordered weight control behaviors, and depressive symptoms among Korean adults: The Korea National Health and Nutrition Examination Survey 2014. PLoS ONE. 2018;13(6):e0198841.

16. Weiss EC, Galuska DA, Khan LK, Serdula MK. Weight-control practices among U.S. adults, 2001-2002. Am J Prev Med. 2006 Jul;31(1):18-24.

17. Thøgersen-Ntoumani C, Ntoumanis N, Cumming J, Chatzisarantis NLD. When feeling attractive matters too much to women: A process underpinning the relation between psychological need satisfaction and unhealthy weight control behaviors. Motivation and Emotion. 2011;35(4):413-22.

18. Sanchez DT, Crocker J. How Investment in Gender Ideals Affects Well-Being: The Role of External Contingencies of Self-Worth. Psychology of Women Quarterly. 2005;29(1):63-77.

19. Sattler KM, Deane FP, Tapsell L, Kelly PJ. Gender differences in the relationship of weightbased stigmatisation with motivation to exercise and physical activity in overweight individuals. Health Psychol Open. 2018 Jun;5(1):2055102918759691.

20. Hunger JM, Major B, Blodorn A, Miller CT. Weighed down by stigma: How weight-based social identity threat contributes to weight gain and poor health. Soc Personal Psychol Compass. 2015 Jun;9(6):255-68.

21. Grabe S, Ward LM, Hyde JS. The role of the media in body image concerns among women: a meta-analysis of experimental and correlational studies. Psychol Bull. 2008 May;134(3):460-76.

22. Nagata JM, Garber AK, Tabler JL, Murray SB, Bibbins-Domingo K. Differential Risk Factors for Unhealthy Weight Control Behaviors by Sex and Weight Status Among U.S. Adolescents. J Adolesc Health. 2018;63(3):335-41.

23. Murray SB, Nagata JM, Griffiths S, Calzo JP, Brown TA, Mitchison D, et al. The enigma of male eating disorders: A critical review and synthesis. Clin Psychol Rev. 2017 Nov;57:1-11.

24. Murray SB, Griffiths S, Nagata JM. Community-Based Eating Disorder Research in Males: A Call to Action. J Adolesc Health. 2018;62(6):649-50.

25. Murray SB, Accurso EC, Griffiths S, Nagata JM. Boys, Biceps, and Bradycardia: The Hidden Dangers of Muscularity-Oriented Disordered Eating. Journal of Adolescent Health. 2018 Mar 1;62(3):352-5.

26. Burmeister JM, Hinman N, Koball A, Hoffmann DA, Carels RA. Food addiction in adults seeking weight loss treatment. Implications for psychosocial health and weight loss. Appetite. 2013 Jan;60(1):103-10. 
27. Carels RA, Hlavka R, Selensky JC, Solar C, Rossi J, Caroline Miller J. A daily diary study of internalised weight bias and its psychological, eating and exercise correlates. Psychol Health. 2019;34(3):306-20.

28. Vartanian LR, Pinkus RT, Smyth JM. Experiences of weight stigma in everyday life: Implications for health motivation. Stigma and Health. 2018;3(2):85-92.

29. Nuttall FQ. Body Mass Index. Nutr Today. 2015 May;50(3):117-28. 


\section{Result Tables}

Table 1. Sample Characteristics

\begin{tabular}{|c|c|c|c|c|}
\hline Variable & Total sample $(\mathrm{N}=161) \mathrm{a}$ & $\begin{array}{l}\text { Women } \\
(\mathrm{N}=85)_{\mathrm{a}}\end{array}$ & $\begin{array}{l}\text { Men } \\
(\mathrm{N}=76)_{a}\end{array}$ & $p_{\mathrm{b}}$ \\
\hline Age, years & $34.32 \pm 17.11$ & $36.58 \pm 18.76$ & $31.80 \pm 18.76$ & 0.07 \\
\hline BMI, kg/m2 & $26.50 \pm 4.99$ & $27.38 \pm 5.64$ & $25.50 \pm 3.94$ & 0.02 \\
\hline $\begin{array}{l}\text { Race/Ethnicity } \\
\text { Caucasian, n (\%) } \\
\text { Non-Caucasian, n (\%) }\end{array}$ & $\begin{array}{l}105(65.20) \\
56(34.80)\end{array}$ & $\begin{array}{l}59(69.40) \\
26(30.60)\end{array}$ & $\begin{array}{l}46(60.50) \\
30(39.50)\end{array}$ & 0.24 \\
\hline $\begin{array}{l}\text { Weight Bias Internalization } \\
\text { Low WBI, n (\%) } \\
\text { High WBI, n }(\%)\end{array}$ & $\begin{array}{l}2.18 \pm 0.92 \\
27(16.80) \\
24(14.90)\end{array}$ & $\begin{array}{l}2.30 \pm 0.93 \\
10(11.80) \\
15(17.60)\end{array}$ & $\begin{array}{l}2.05 \pm 0.89 \\
17(22.40) \\
9(11.80)\end{array}$ & $\begin{array}{l}0.09 \\
0.15 \\
0.15\end{array}$ \\
\hline $\begin{array}{l}\text { Weight Perception, n (\%) } \\
\text { Accurate Estimation } \\
\text { Over Estimation } \\
\text { Under Estimation }\end{array}$ & $\begin{array}{l}100(62.10) \\
22(13.70) \\
39(24.20)\end{array}$ & $\begin{array}{l}56(65.90) \\
15(17.60) \\
14(16.50)\end{array}$ & $\begin{array}{l}44(57.90) \\
7(9.20) \\
25(32.90)\end{array}$ & 0.03 \\
\hline $\begin{array}{l}\text { Healthy Weight Control } \\
\text { Behaviours }\end{array}$ & $4.68 \pm 1.69$ & $4.82 \pm 1.53$ & $4.51 \pm 1.86$ & 0.25 \\
\hline $\begin{array}{l}\text { Additive Healthy Weight Control } \\
\text { Behaviours } \\
\text { Exercise, n (\%) } \\
\text { Fruits \& Veg., n (\%) }\end{array}$ & $\begin{array}{l}1.75 \pm 0.57 \\
143(88.80) \\
139(86.30)\end{array}$ & $\begin{array}{l}1.81 \pm 0.50 \\
76(89.40) \\
78(91.80)\end{array}$ & $\begin{array}{l}1.68 \pm 0.64 \\
67(88.20) \\
61(80.30)\end{array}$ & 0.36 \\
\hline $\begin{array}{l}\text { Restrictive Healthy Weight } \\
\text { Control Behaviours } \\
\text { Fewer Fat Foods, n (\%) } \\
\text { Fewer Sweets, n (\%) } \\
\text { Less Soda, n (\%) } \\
\text { Serving Sized, n (\%) }\end{array}$ & $\begin{array}{l}2.93 \pm 1.28 \\
114(70.80) \\
128(79.50) \\
129(80.10) \\
100(62.10)\end{array}$ & $\begin{array}{l}3.01 \pm 1.20 \\
66(77.60) \\
68(80.00) \\
68(80.00) \\
54(63.50)\end{array}$ & $\begin{array}{l}2.83 \pm 1.37 \\
48(63.20) \\
60(78.90) \\
61(80.30) \\
46(60.50)\end{array}$ & 0.75 \\
\hline $\begin{array}{l}\text { Unhealthy \& Extreme Weight } \\
\text { Control Behaviours }\end{array}$ & $1.18 \pm 1.34$ & $1.20 \pm 1.43$ & $1.16 \pm 1.23$ & 0.29 \\
\hline $\begin{array}{l}\text { Unhealthy Weight Control } \\
\text { Behaviours }\end{array}$ & $1.07 \pm 1.23$ & $1.01 \pm 1.24$ & $1.13 \pm 1.22$ & 0.48 \\
\hline $\begin{array}{l}\text { Fasted, n (\%) } \\
\text { Little Food, n (\%) } \\
\text { Food Substitutes, n (\%) } \\
\text { Skipped Meals, n (\%) }\end{array}$ & $\begin{array}{l}35(21.70) \\
57(35.40) \\
28(17.40) \\
52(32.30)\end{array}$ & $\begin{array}{l}15(17.60) \\
30(35.30) \\
16(18.80) \\
25(29.40)\end{array}$ & $\begin{array}{l}20(26.30) \\
27(35.50) \\
12(15.80) \\
27(35.50)\end{array}$ & \\
\hline $\begin{array}{l}\text { Extreme Weight Control } \\
\text { Behaviours }\end{array}$ & $0.11 \pm 1.34$ & $0.19 \pm 0.52$ & $0.03 \pm 0.23$ & $<0.0001$ \\
\hline $\begin{array}{l}\text { At least one behaviour, n (\%) } \\
\text { Diet Pills, n (\%) } \\
\text { Vomit, n (\%) } \\
\text { Laxatives, n (\%) } \\
\text { Diuretics, n }(\%) \\
\end{array}$ & $\begin{array}{l}13(8.10) \\
8(4.90) \\
5(3.10) \\
2(1.20) \\
3(1.90) \\
\end{array}$ & $\begin{array}{l}12(14.10) \\
7(8.20) \\
5(5.90) \\
2(2.40) \\
2(2.40) \\
\end{array}$ & $\begin{array}{l}1(1.30) \\
1(1.30) \\
0 \\
0 \\
1(1.30) \\
\end{array}$ & 0.003 \\
\hline
\end{tabular}

aMean + standard deviation unless indicated otherwise; $b$ Women compared to Men 
Table 2. Multiple Linear Regressions: WBI and Healthy Weight Control Behaviours

\begin{tabular}{|c|c|c|c|}
\hline Variable & $\begin{array}{l}\text { Healthy Weight } \\
\text { Control Behaviours } \\
\text { (B) (SE) }\end{array}$ & $\begin{array}{l}\text { Additive Healthy } \\
\text { Weight Control } \\
\text { Behaviours } \\
\text { (B) (SE) }\end{array}$ & $\begin{array}{c}\text { Restrictive Healthy } \\
\text { Weight Control } \\
\text { Behaviours } \\
\text { (B) (SE) }\end{array}$ \\
\hline \multicolumn{4}{|c|}{ Total Sample $(\mathrm{N}=161)$} \\
\hline Mean WBIa & $0.29(0.15)$ & $0.11(0.05) *$ & $0.18(0.11)$ \\
\hline Weight Underestimation $b$ & $0.22(0.32)$ & $0.06(0.11)$ & $0.16(0.24)$ \\
\hline Weight Overestimationb & $0.31(0.40)$ & $0.06(0.13)$ & $0.26(0.30)$ \\
\hline \multicolumn{4}{|c|}{$\operatorname{Men}(\mathrm{N}=76)$} \\
\hline Mean WBIa & $0.29(0.25)$ & $0.07(0.09)$ & $0.22(0.19)$ \\
\hline Weight Underestimation $\mathrm{b}$ & $-0.10(0.48)$ & $-0.10(0.16)$ & $0.001(0.35)$ \\
\hline Weight Overestimationb & $0.53(0.78)$ & $0.13(0.27)$ & $0.40(0.57)$ \\
\hline \multicolumn{4}{|c|}{ Women $(\mathrm{N}=85)$} \\
\hline Mean WBIa & $0.26(0.18)$ & $0.13(0.06) *$ & $0.13(0.14)$ \\
\hline Weight Underestimation $b$ & $0.69(0.45)$ & $0.27(0.15)$ & $0.42(0.35)$ \\
\hline Weight Overestimation & $0.23(0.44)$ & $0.06(0.15)$ & $0.17(0.34)$ \\
\hline
\end{tabular}

Note: $\mathrm{B}=$ parameter estimate, $*=\mathrm{p}<0.05, * *=\mathrm{p}<0.01, * * *=\mathrm{p}<0.001, * * * *=\mathrm{p}<0.0001$

Note: Additive healthy weight control behaviours include performing exercise $\&$ consuming fruits \& vegetables

Note: Restrictive healthy weight control behaviours include consuming fewer high fat foods, sweets, less soda and controlling portion sizes

aAdjusted for age, sex \& race (Caucasian vs. non-Caucasian), and other predictors shown here (mean WBI, weight perception) in a single model

bReference level: accurate estimation 
Table 3. Multiple Logistic Regressions: WBI and Healthy Weight Control Behaviours

\begin{tabular}{|c|c|c|c|c|c|c|}
\hline Variable & $\begin{array}{c}\text { Exercise } \\
\text { (OR) }[95 \% \mathrm{CI}]\end{array}$ & $\begin{array}{c}\text { Fruits \& } \\
\text { Vegetables (OR) } \\
{[95 \% \mathrm{CI}]} \\
\end{array}$ & $\begin{array}{c}\text { Less High-Fat } \\
\text { Food } \\
\text { (OR) }[95 \% \mathrm{CI}]\end{array}$ & $\begin{array}{c}\text { Less Sweets (OR) } \\
{[95 \% \mathrm{CI}]}\end{array}$ & $\begin{array}{c}\text { Less Soda (OR) } \\
{[95 \% \mathrm{CI}]}\end{array}$ & $\begin{array}{l}\text { Serving Sizes } \\
(\mathrm{OR})[95 \% \mathrm{CI}]\end{array}$ \\
\hline \multicolumn{7}{|c|}{ Total Sample $(\mathrm{N}=161)$} \\
\hline Mean WBIa & $2.20[1.05,4.64]^{*}$ & $1.66[0.90,3.04]$ & $1.26[0.84,1.89]$ & $1.31[0.83,2.08]$ & $1.20[0.76,1.91]$ & $1.33[0.91,1.96]$ \\
\hline $\begin{array}{l}\text { Weight } \\
\text { Underestimationb }\end{array}$ & $0.96[0.29,3.19]$ & $1.71[0.55,5.37]$ & $1.33[0.55,3.22]$ & $1.14[0.43,3.01]$ & $1.01[0.40,2.56]$ & $1.60[0.68,3.76]$ \\
\hline $\begin{array}{l}\text { Weight } \\
\text { Overestimationb }\end{array}$ & $1.20[0.23,6.21]$ & $1.54[0.31,7.60]$ & $1.04[0.35,3.09]$ & $1.21[0.36,4.09]$ & $6.54[0.82,52.02]$ & $1.24[0.45,3.40]$ \\
\hline \multicolumn{7}{|c|}{$\operatorname{Men}(\mathbf{N}=76)$} \\
\hline Mean WBIa & $1.43[0.45,4.56]$ & $1.40[0.66,2.94]$ & $1.15[0.64,2.05]$ & $1.73[0.80,3.76]$ & $1.86[0.79,4.35]$ & $1.19[0.68,2.08]$ \\
\hline $\begin{array}{l}\text { Weight } \\
\text { Underestimationb }\end{array}$ & $0.37[0.07,1.82]$ & $1.14[0.32,3.99]$ & $0.84[0.29,2.43]$ & $0.97[0.29,3.32]$ & $1.00[0.29,3.46]$ & $1.30[0.45,3.78]$ \\
\hline $\begin{array}{l}\text { Weight } \\
\text { Overestimationb }\end{array}$ & NA & $1.40[0.14,13.86]$ & $1.45[0.24,8.86]$ & $1.71[0.17,17.28]$ & NA & $1.13[0.21,5.95]$ \\
\hline \multicolumn{7}{|c|}{ Women $(\mathrm{N}=85)$} \\
\hline Mean WBIa & $2.92[0.94,9.06]$ & $2.37[0.77,7.34]$ & $1.41[0.75,2.66]$ & $1.09[0.60,1.99]$ & $0.90[0.50,1.62]$ & $1.48[0.85,2.59]$ \\
\hline $\begin{array}{l}\text { Weight } \\
\text { Underestimationb }\end{array}$ & NA & NA & $5.99[0.65,55.13]$ & $1.77[0.33,9.60]$ & $1.12[0.26,4.80]$ & $2.30[0.52,9.78]$ \\
\hline $\begin{array}{l}\text { Weight } \\
\text { Overestimationb }\end{array}$ & $0.97[0.94,9.06]$ & $1.76[0.19,16.31]$ & $0.78[0.19,3.24]$ & $0.93[0.21,4.15]$ & $4.62[0.54,39.92]$ & $1.33[0.36,4.98]$ \\
\hline
\end{tabular}

Note: $\mathrm{OR}=$ parameter estimate, $*=\mathrm{p}<0.05, * *=\mathrm{p}<0.01, * * *=\mathrm{p}<0.001, * * * *=\mathrm{p}<0.0001$

NA: Results not available due to insufficient sample size for specific behaviours when stratified by sex

aAdjusted for age, sex \& race (Caucasian vs. non-Caucasian), and other predictors shown here (mean WBI, weight perception) in a single model

bReference level: accurate estimation 
Table 4. Multiple Linear \& Logistic Regressions: WBI and Unhealthy \& Extreme Weight Control Behaviours

\begin{tabular}{|c|c|c|c|}
\hline & $\begin{array}{l}\text { Linear Regression } \\
\text { (B) (SE) }\end{array}$ & $\begin{array}{c}\text { Linear Regression } \\
\text { (B) (SE) }\end{array}$ & $\begin{array}{l}\text { Logistic Regression } \\
\text { (OR) }[95 \% \mathrm{CI}]\end{array}$ \\
\hline Variable & $\begin{array}{c}\text { Unhealthy \& Extreme Weight } \\
\text { Control Behaviours }\end{array}$ & $\begin{array}{c}\text { Unhealthy Weight Control } \\
\text { Behaviours }\end{array}$ & $\begin{array}{c}\text { Extreme Weight Control } \\
\text { Behaviours }\end{array}$ \\
\hline \multicolumn{4}{|c|}{ Total Sample $(\mathrm{N}=161)$} \\
\hline Mean WBIa & $0.49(0.11)^{* * * *}$ & $0.37(0.10)^{* * *}$ & $2.66[1.33,5.33]^{* *}$ \\
\hline Weight Underestimationb & $-0.14(0.24)$ & $-0.16(0.23)$ & $0.64[0.07,6.29]$ \\
\hline Weight Overestimationb & $0.40(0.30)$ & $0.29(0.28)$ & $4.00[0.89,17.96]$ \\
\hline \multicolumn{4}{|c|}{ Men $(N=76)$} \\
\hline Mean WBIa & $0.45(0.16)^{* *}$ & $0.40(0.16)^{*}$ & NA \\
\hline Weight Underestimationb & $-0.35(0.30)$ & $-0.36(0.30)$ & NA \\
\hline Weight Overestimationb & $0.003(0.48)$ & $-0.26(0.48)$ & NA \\
\hline \multicolumn{4}{|c|}{ Women $(\mathrm{N}=\mathbf{8 5})$} \\
\hline Mean WBIa & $0.55(0.16)^{* *}$ & $0.39(0.14) * *$ & $2.34[1.13,4.83]^{*}$ \\
\hline Weight Underestimationb & $0.13(0.40)$ & $0.13(0.36)$ & $0.62[0.06,6.07]$ \\
\hline Weight Overestimationb & $0.63(0.40)$ & $0.58(0.35)$ & $2.73[0.53,14.03]$ \\
\hline
\end{tabular}

Note: $\mathrm{B}=$ parameter estimate, $\mathrm{OR}=$ parameter estimate, $*=\mathrm{p}<0.05, * *=\mathrm{p}<0.01, * * *=\mathrm{p}<0.001, * * * *=\mathrm{p}<0.0001$ Note: Logistic regression: likelihood of performing at least one extreme weight control behaviour Note: Unhealthy weight control behaviours include fasting, eating little amounts of food, taking food substitutes \& skipping meals

Note: Extreme weight control behaviours include taking diet pills, laxatives, diuretics \& vomiting

NA: Results not available due to insufficient sample size for specific behaviours when stratified by sex

aAdjusted for age, sex \& race (Caucasian vs. non-Caucasian), and other predictors shown here (mean WBI, weight perception) in a single model

bReference level: accurate estimation 
Table 5. Multiple Logistic Regressions: WBI and Unhealthy Weight Control Behaviours

\begin{tabular}{|c|c|c|c|c|}
\hline Variable & $\begin{array}{c}\text { Fasted } \\
(\mathrm{OR})[95 \% \mathrm{CI}]\end{array}$ & $\begin{array}{c}\text { Little Food } \\
\text { (OR) }[95 \% \text { CI] }\end{array}$ & $\begin{array}{c}\text { Food Substitutes } \\
\text { (OR) }[95 \% \text { CI] }\end{array}$ & $\begin{array}{l}\text { Skipped Meals } \\
\text { (OR) [95\% CI] }\end{array}$ \\
\hline \multicolumn{5}{|c|}{ Total Sample $(\mathrm{N}=161)$} \\
\hline Mean WBIa & $1.31[0.87,1.99]$ & $1.67[1.13,2.47] * *$ & $1.66[1.06,2.59]^{*}$ & $1.92[1.29,2.87] * *$ \\
\hline $\begin{array}{l}\text { Weight } \\
\text { Underestimationb }\end{array}$ & $0.71[0.26,1.92]$ & $0.64[0.26,1.56]$ & $1.09[0.38,3.17]$ & $0.86[0.35,2.09]$ \\
\hline $\begin{array}{l}\text { Weight } \\
\text { Overestimationb }\end{array}$ & $0.73[0.21,2.50]$ & $2.54[0.94,6.85]$ & $1.17[0.34,4.01]$ & $1.74[0.63,4.82]$ \\
\hline \multicolumn{5}{|c|}{$\operatorname{Men}(N=76)$} \\
\hline Mean WBIa & $1.11[0.60,2.06]$ & $2.33[1.24,4.38]^{* *}$ & $2.18[0.99,4.78]$ & $1.61[0.91,2.88]$ \\
\hline $\begin{array}{l}\text { Weight } \\
\text { Underestimationb }\end{array}$ & $0.56[0.16,1.94]$ & $0.49[0.15,1.65]$ & $1.64[0.37,7.36]$ & $0.40[0.12,1.31]$ \\
\hline $\begin{array}{l}\text { Weight } \\
\text { Overestimationb }\end{array}$ & $0.25[0.03,2.36]$ & $1.50[0.25,8.99]$ & $0.87[0.08,9.76]$ & $0.73[0.13,4.01]$ \\
\hline \multicolumn{5}{|c|}{ Women $(\mathrm{N}=\mathbf{8 5})$} \\
\hline Mean WBIa & $1.77[0.94,3.31]$ & $1.33[0.80,2.23]$ & $1.60[0.88,2.92]$ & $2.51[1.37,4.60] * *$ \\
\hline $\begin{array}{l}\text { Weight } \\
\text { Underestimationb }\end{array}$ & $0.98[0.17,5.57]$ & $0.94[0.25,3.60]$ & $0.81[0.15,4.33]$ & $2.71[0.66,11.12]$ \\
\hline $\begin{array}{l}\text { Weight } \\
\text { Overestimationb }\end{array}$ & $1.77[0.37,8.34]$ & $3.27[0.93,11.44]$ & $1.30[0.29,5.71]$ & $3.60[0.94,13.68]$ \\
\hline
\end{tabular}

Note: $\mathrm{OR}=$ parameter estimate, $*=\mathrm{p}<0.05, * *=\mathrm{p}<0.01, * * *=\mathrm{p}<0.001, * * * *=\mathrm{p}<0.0001$

aAdjusted for age, sex \& race (Caucasian vs. non-Caucasian), and other predictors shown here (mean WBI, weight perception) in a single model

bReference level: accurate estimation 


\subsection{Additional Results}

This section describes findings that were not included within the manuscript and those obtained as part of the additional results where participants with BMI values within $1 \mathrm{~kg} / \mathrm{m} 2 \mathrm{of}$ the classification cut-offs were eliminated. These results were not included within the main results of the manuscript due to journal constraints.

\subsection{Sensitivity Analysis Results}

For the primary analysis previously presented, the following objectively measured BMI classifications were used, according to the National Institute of Health: underweight $(<18.5$ $\left.\mathrm{kg} / \mathrm{m}_{2}\right)$, normal weight $\left(18.5 \mathrm{~kg} / \mathrm{m}_{2}-24.9 \mathrm{~kg} / \mathrm{m}_{2}\right)$, overweight $\left(25 \mathrm{~kg} / \mathrm{m}_{2}-29.9 \mathrm{~kg} / \mathrm{m}_{2}\right)$ and obesity $(>30 \mathrm{~kg} / \mathrm{m} 2)(63)$. However, as BMI is a crude measurement, a sensitivity analysis eliminating those who had BMI values within $1 \mathrm{~kg} / \mathrm{m} 2$ of each BMI classification cut-off was conducted.

There were 48 participants who were removed from further analyses because they were within $1 \mathrm{~kg} / \mathrm{m} 2$ of the BMI classification cut-off values, which included 27 men and 21 women. Among the 48 participants who were eliminated, 30 were within $1 \mathrm{~kg} / \mathrm{m} 2$ of the normal weight BMI classification and 18 were within $1 \mathrm{~kg} / \mathrm{m} 2$ of the overweight BMI classification. There were no participants with BMI values within $1 \mathrm{~kg} / \mathrm{m} 2$ of the obesity BMI classification. The distribution of participants within each group is described in Table 6. Moreover, among those eliminated, only $54 \%$ had accurately perceived their weight status.

Within this new sample, mean WBI from the adjusted linear regression models was significantly associated with the number of additive healthy weight control behaviours performed $(\mathrm{B}=0.13, \mathrm{p}<0.05$, Table 7$)$, which was consistent with the main findings. However, when examining the relationship between mean WBI and the likelihood of performing any of the specific healthy weight control behaviours, there were no significant associations (Table 8). However, the magnitude and direction for the relationship between mean WBI and the likelihood of performing exercise was very similar to the results obtained within the primary analysis (primary $\mathrm{OR}=2.20[1.05,4.64]$ vs. sensitivity $\mathrm{OR}=1.88[0.85,4.16])$. Consistent with the main findings, mean WBI was significantly associated with the number of combined unhealthy and 
extreme weight control behaviours within the total population, as well as in men and women $(\mathrm{B}=0.58, \mathrm{p}<0.0001 ; \mathrm{B}=0.45, \mathrm{p}<0.05$ and $\mathrm{B}=0.68, \mathrm{p}<0.001$, respectively, Table 9). When examining the relationship between mean WBI and unhealthy weight control behaviours alone, there were only significant positive relationships within this full sample, and among women $(B=0.43, p<0.01$ and $B=0.50, p<0.01$, respectively, Table 9). In contrast, this relationship was significant among men in the main study findings, however, the magnitude and direction remained very similar to those obtained in the primary analysis (primary $B=0.40(0.16)$ vs. sensitivity $B=0.35(0.20)$ ). Lastly, consistent with the main findings, mean WBI in the sensitivity analysis was significantly associated with an increased likelihood of consuming little amounts of food, taking food substitutes and skipping meals within the entire population $(\mathrm{OR}=1.66[95 \% \mathrm{CI}$ : 1.07, 2.60], $\mathrm{p}<0.05 ; \mathrm{OR}=1.79$ [95\% CI: 1.08, 3.00], $\mathrm{p}<0.05 ; \mathrm{OR}=1.97$ [95\% CI: 1.24, 3.13], $\mathrm{p}<0.01$, respectively, Table 10). Upon stratifying by sex, mean WBI was significantly associated with eating little amounts of food in men $(\mathrm{OR}=2.22$ [95\% CI: 1.05, 4.71], p<0.05, Table 10), and skipping meals in women (OR=2.98 [95\% CI: 1.47, 6.03], $\mathrm{p}<0.01$, Table 10).

There were no significant associations between weight perception and weight control behaviours, similar to the main findings.

\subsection{Additional Results Tables from Sensitivity Analysis}

Table 6. Distribution of participants within $1 \mathrm{~kg} / \mathrm{m} 2$ of each BMI classification cut-off (eliminated participants)

\begin{tabular}{lc}
\hline BMI Classification & Participants within $\pm \mathbf{~ k g} / \mathbf{m} 2$ of cut-off \\
\hline Normal Weight $\left(18.5-24.9 \mathrm{~kg} / \mathrm{m}_{2}\right)$ & 30 \\
Overweight $\left(25-29.9 \mathrm{~kg} / \mathrm{m}_{2}\right)$ & 18 \\
Obesity $\left(>30 \mathrm{~kg} / \mathrm{m}_{2}\right)$ & 0 \\
\hline
\end{tabular}


Table 7. Multiple Linear Regressions: WBI and Healthy Weight Control Behaviours $\ddagger$

\begin{tabular}{|c|c|c|c|}
\hline Variable & $\begin{array}{l}\text { Healthy Weight Control } \\
\text { Behaviours (B) (SE) }\end{array}$ & $\begin{array}{l}\text { Additive Healthy Weight } \\
\text { Control Behaviours (B) } \\
\text { (SE) }\end{array}$ & $\begin{array}{c}\text { Restrictive Healthy } \\
\text { Weight Control } \\
\text { Behaviours (B) (SE) }\end{array}$ \\
\hline \multicolumn{4}{|c|}{ Total Sample $(\mathrm{N}=113)$} \\
\hline Mean WBIa & $0.29(0.17)$ & $0.13(0.06)^{*}$ & $0.16(0.13)$ \\
\hline Weight Underestimationb & $0.29(0.38)$ & $0.18(0.13)$ & $0.11(0.29)$ \\
\hline Weight Overestimationb & $0.35(0.50)$ & $0.09(0.17)$ & $0.26(0.37)$ \\
\hline \multicolumn{4}{|c|}{ Men $(N=49)$} \\
\hline Mean WBI a & $0.29(0.29)$ & $0.09(0.11)$ & $0.19(0.21)$ \\
\hline Weight Underestimationb & $-0.20(0.61)$ & $0.06(0.22)$ & $-0.26(0.45)$ \\
\hline Weight Overestimationb & $0.08(0.97)$ & $0.06(0.36)$ & $0.02(0.71)$ \\
\hline \multicolumn{4}{|c|}{ Women $(N=64)$} \\
\hline Mean WBI a & $0.29(0.22)$ & $0.14(0.07)$ & $0.14(0.17)$ \\
\hline Weight Underestimationb & $0.66(0.53)$ & $0.29(0.17)$ & $0.37(0.41)$ \\
\hline Weight Overestimationb & $0.47(0.60)$ & $0.14(0.19)$ & $0.33(0.46)$ \\
\hline
\end{tabular}

Note: $\mathrm{B}=$ parameter estimate, $*=\mathrm{p}<0.05, * *=\mathrm{p}<0.01, * * *=\mathrm{p}<0.001, * * * *=\mathrm{p}<0.0001$

Note: Additive healthy weight control behaviours include performing exercise \& consuming fruits \& vegetables

Note: Restrictive healthy weight control behaviours include consuming fewer high fat foods, sweets, less soda and controlling portion sizes

aAdjusted for age, sex \& race (Caucasian vs. non-Caucasian), and other predictors shown here (mean WBI, weight perception) in a single model

bReference level: accurate estimation

\# Excluding participants within $1 \mathrm{~kg} / \mathrm{m} 2$ of BMI classification cut-off values 
Table 8. Multiple Logistic Regressions: WBI and Healthy Weight Control Behaviours $¥$

\begin{tabular}{|c|c|c|c|c|c|c|}
\hline Variable & $\begin{array}{c}\text { Exercise (OR) } \\
{[95 \% \text { CI] }}\end{array}$ & $\begin{array}{c}\text { Fruits \& } \\
\text { Vegetables (OR) } \\
{[95 \% \text { CI] }}\end{array}$ & $\begin{array}{c}\text { Less High-Fat } \\
\text { Food (OR) } \\
{[95 \% \text { CI] }}\end{array}$ & $\begin{array}{l}\text { Less Sweets } \\
\text { (OR) [95\% CI] }\end{array}$ & $\begin{array}{c}\text { Less Soda (OR) } \\
{[95 \% \mathrm{CI}]}\end{array}$ & $\begin{array}{l}\text { Serving Sizes } \\
\text { (OR) }[95 \% \text { CI }]\end{array}$ \\
\hline \multicolumn{7}{|c|}{ Total Sample $(\mathrm{N}=113)$} \\
\hline Mean WBIa & $1.88[0.85,4.16]$ & $2.37[0.98,5.69]$ & $1.22[0.74,2.02]$ & $1.21[0.69,2.13]$ & $1.20[0.70,2.04]$ & $1.37[0.86,2.20]$ \\
\hline $\begin{array}{l}\text { Weight } \\
\text { Underestimationb }\end{array}$ & $1.63[0.32,8.46]$ & $5.28[0.60,46.36]$ & $1.03[0.35,3.02]$ & $0.89[0.27,2.91]$ & $1.20[0.38,3.79]$ & $1.65[0.58,4.70]$ \\
\hline $\begin{array}{l}\text { Weight } \\
\text { Overestimationb }\end{array}$ & $\begin{array}{c}1.52 \\
{[0.16,14.19]}\end{array}$ & $2.16[0.23,20.32]$ & $1.64[0.30,8.88]$ & $1.04[0.19,5.60]$ & $\begin{array}{c}5.29 \\
{[0.60,46.42]}\end{array}$ & $1.05[0.28,3.92]$ \\
\hline \multicolumn{7}{|c|}{ Men $(N=49)$} \\
\hline Mean WBIa & $1.53[0.45,5.30]$ & $1.64[0.60,4.52]$ & $1.15[0.54,2.45]$ & $1.43[0.52,3.91]$ & $2.10[0.65,6.81]$ & $1.21[0.59,2.45]$ \\
\hline $\begin{array}{l}\text { Weight } \\
\text { Underestimationb }\end{array}$ & $0.50[0.06,3.92]$ & $3.38[0.32,35.71]$ & $0.28[0.05,1.41]$ & $0.58[0.10,3.56]$ & $\begin{array}{c}2.15 \\
{[0.30,15.47]}\end{array}$ & $0.86[0.20,3.78]$ \\
\hline $\begin{array}{l}\text { Weight } \\
\text { Overestimation }\end{array}$ & NA & $0.99[0.07,13.66]$ & $\begin{array}{c}0.76 \\
{[0.05,11.39]}\end{array}$ & $0.61[0.04,8.64]$ & NA & $0.62[0.07,5.89]$ \\
\hline \multicolumn{7}{|c|}{ Women $(\mathrm{N}=64)$} \\
\hline Mean WBIa & $2.44[0.71,8.32]$ & $3.58[0.69,18.49]$ & $1.43[0.67,3.03]$ & $1.11[0.57,2.19]$ & $0.95[0.51,1.77]$ & $1.59[0.81,3.13]$ \\
\hline $\begin{array}{l}\text { Weight } \\
\text { Underestimationb }\end{array}$ & NA & NA & $\begin{array}{c}4.38 \\
{[0.47,41.31]}\end{array}$ & $1.55[0.27,8.83]$ & $1.05[0.24,4.70]$ & $\begin{array}{c}2.31 \\
{[0.44,12.14]}\end{array}$ \\
\hline $\begin{array}{l}\text { Weight } \\
\text { Overestimationb }\end{array}$ & $\begin{array}{c}0.93 \\
{[0.08,10.57]}\end{array}$ & NA & $\begin{array}{c}1.72 \\
{[0.17,17.55]}\end{array}$ & $1.49[0.15,14.95]$ & $\begin{array}{c}3.94 \\
{[0.41,38.39]}\end{array}$ & $1.24[0.22,6.94]$ \\
\hline
\end{tabular}

Note: $\mathrm{OR}=$ parameter estimate, $*=\mathrm{p}<0.05, * *=\mathrm{p}<0.01, * * *=\mathrm{p}<0.001, * * * *=\mathrm{p}<0.0001$

NA: Results not available due to insufficient sample size for specific behaviours when stratified by sex

aAdjusted for age, sex \& race (Caucasian vs. non-Caucasian), and other predictors shown here (mean WBI, weight perception) in a single model

bReference level: accurate estimation

\# Excluding participants within $1 \mathrm{~kg} / \mathrm{m} 2$ of BMI classification cut-off values 
Table 9. Multiple Linear Regressions: WBI and Unhealthy \& Extreme Weight Control Behaviours

\begin{tabular}{|c|c|c|}
\hline Variable & $\begin{array}{l}\text { Unhealthy \& Extreme Weight } \\
\text { Control Behaviours (B) (SE) }\end{array}$ & $\begin{array}{c}\text { Unhealthy Weight Control } \\
\text { Behaviours (B) (SE) }\end{array}$ \\
\hline \multicolumn{3}{|c|}{ Total Sample $(\mathrm{N}=113)$} \\
\hline Mean WBIa & $0.58(0.14) * * * *$ & $0.43(0.13)^{* *}$ \\
\hline Weight Underestimationb & $-0.17(0.30)$ & $-0.20(0.29)$ \\
\hline Weight Overestimationb & $-0.05(0.39)$ & $-0.20(0.37)$ \\
\hline \multicolumn{3}{|c|}{$\operatorname{Men}(\mathrm{N}=49)$} \\
\hline Mean WBIa & $0.45(0.21) *$ & $0.35(0.20)$ \\
\hline Weight Underestimation $b$ & $-0.46(0.45)$ & $-0.46(0.45)$ \\
\hline Weight Overestimationb & $-0.12(0.71)$ & $-0.60(0.71)$ \\
\hline \multicolumn{3}{|c|}{ Women $(N=64)$} \\
\hline Mean WBIa & $0.68(0.18) * * *$ & $0.50(0.17)^{* *}$ \\
\hline Weight Underestimation $b$ & $0.07(0.44)$ & $0.02(0.40)$ \\
\hline Weight Overestimationb & $-0.10(0.50)$ & $-0.08(0.17)$ \\
\hline
\end{tabular}

\footnotetext{
Note: $\mathrm{B}=$ parameter estimate, $*=\mathrm{p}<0.05, * *=\mathrm{p}<0.01, * * *=\mathrm{p}<0.001, * * * *=\mathrm{p}<0.0001$

Note: Unhealthy weight control behaviours include fasting, eating little amounts of food, taking food substitutes \& skipping meals

Note: Extreme weight control behaviours include taking diet pills, laxatives, diuretics \& vomiting aAdjusted for age, sex \& race (Caucasian vs. non-Caucasian), and other predictors shown here (mean WBI, weight perception) in a single model

bReference level: accurate estimation

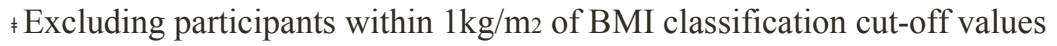


Table 10. Multiple Logistic Regressions: WBI and Unhealthy Weight Control Behaviours $\ddagger$

\begin{tabular}{|c|c|c|c|c|}
\hline Variable & Fasted (OR) $[95 \% \mathrm{CI}]$ & $\begin{array}{c}\text { Little Food (OR) [95\% } \\
\text { CI] }\end{array}$ & $\begin{array}{c}\text { Food Substitutes (OR) } \\
{[95 \% \mathrm{CI}]}\end{array}$ & $\begin{array}{c}\text { Skipped Meals (OR) } \\
{[95 \% \mathrm{CI}]}\end{array}$ \\
\hline \multicolumn{5}{|c|}{ Total Sample $(\mathrm{N}=161)$} \\
\hline Mean WBI a & $1.46[0.90,2.37]$ & $1.66 *[1.07,2.60]$ & $1.79 *[1.08,3.00]$ & $1.97 * *[1.24,3.13]$ \\
\hline $\begin{array}{l}\text { Weight } \\
\text { Underestimation }\end{array}$ & $0.79[0.26,2.46]$ & $0.64[0.23,1.80]$ & $1.07[0.33,3.52]$ & $0.69[0.25,1.91]$ \\
\hline $\begin{array}{l}\text { Weight } \\
\text { Overestimation }\end{array}$ & $0.54[0.10,3.02]$ & $1.05[0.29,3.80]$ & $0.97[0.18,5.31]$ & $0.48[0.11,2.09]$ \\
\hline \multicolumn{5}{|c|}{$\operatorname{Men}(N=76)$} \\
\hline Mean WBI a & $1.12[0.54,2.32]$ & $2.22 *[1.05,4.71]$ & $1.83[0.77,4.39]$ & $1.32[0.65,2.69]$ \\
\hline $\begin{array}{l}\text { Weight } \\
\text { Underestimation }\end{array}$ & $0.86[0.18,4.08]$ & $0.40[0.08,2.09]$ & $1.85[0.31,11.13]$ & $0.19[0.03,1.05]$ \\
\hline $\begin{array}{l}\text { Weight } \\
\text { Overestimation }\end{array}$ & $0.52[0.04,6.39]$ & $1.40[0.12,16.44]$ & NA & $0.16[0.01,2.22]$ \\
\hline \multicolumn{5}{|c|}{ Women $(\mathrm{N}=\mathbf{8 5})$} \\
\hline Mean WBI a & $1.90[0.95,3.80]$ & $1.36[0.77,2.39]$ & $1.87[0.96,3.63]$ & $2.98 * *[1.47,6.03]$ \\
\hline $\begin{array}{l}\text { Weight } \\
\text { Underestimation }\end{array}$ & $0.91[0.15,5.46]$ & $0.94[0.23,3.75]$ & $0.76[0.13,4.54]$ & $1.85[0.43,8.07]$ \\
\hline $\begin{array}{l}\text { Weight } \\
\text { Overestimation }\end{array}$ & $0.59[0.06,6.32]$ & $1.03[0.21,5.11]$ & $1.60[0.24,10.56]$ & $0.76[0.12,4.74]$ \\
\hline
\end{tabular}

Note: $\mathrm{OR}=$ parameter estimate, $*=\mathrm{p}<0.05, * *=\mathrm{p}<0.01, * * *=\mathrm{p}<0.001, * * * *=\mathrm{p}<0.0001$

NA: Results not available due to insufficient sample size for specific behaviours when stratified by sex

aAdjusted for age, sex \& race (Caucasian vs. non-Caucasian), and other predictors shown here (mean WBI, weight perception) in a single model

bReference level: accurate estimation

‡ Excluding participants within $1 \mathrm{~kg} / \mathrm{m}_{2}$ of BMI classification cut-off values 


\section{CHAPTER 4: DISCUSSION}

The purpose of this study was to assess the relationship between WBI and the use of healthy and unhealthy weight control behaviours in a sample of Canadian men and women of three objectively measured weight statuses. We also examined the relationship between weight misperception and weight control behaviours. Results from these analyses were described within the manuscript in Chapter 3 of this thesis. This discussion highlights the main results presented in the manuscript, as well as the additional results reported from the sensitivity analysis.

In terms of the relationship between WBI and various healthy and unhealthy weight control behaviours, it was originally hypothesized that mean WBI would be negatively associated with healthy weight control behaviours but positively associated with unhealthy and extreme weight control behaviours. Our results demonstrated that WBI was significantly associated with the number of additive healthy weight control behaviours performed, specifically, performing exercise for weight control. WBI was also significantly associated with the total number of unhealthy weight control behaviours, as well as the combination of unhealthy and extreme weight control behaviours. More precisely, mean WBI was significantly associated with performing unhealthy weight control behaviours such as eating little amounts of food, taking food substitutes and skipping meals. These results reject the hypothesized negative relationship between WBI and healthy weight control behaviours but were consistent with the hypothesized positive relationship between WBI and unhealthy weight control behaviours. Despite many studies reporting a negative relationship between WBI and various aspects of health (12), the current study showed that WBI was associated with additive healthy weight control behaviours that individuals perform, especially exercise. However, more research is needed to further investigate this relationship as our study only portrays behaviours that have been performed within the previous year. Additional research is needed to elucidate the specific healthy behaviours individuals perform in their everyday lives in order to improve health.

Only one known previous study has examined the relationship between WBI and the specific weight control behaviours that individuals performed in order to control their weight (28). This relationship is important to understand because it informs researchers and healthcare professionals on precise behavioural correlates associated with WBI in order to hopefully lead to being able to better target and treat unhealthy behaviours with the aim of improving the overall 
health of patients. Much of the previous research has been heavily concentrated on motivations or desires to control one's weight rather than examining the specific types of behaviours that were being performed $(15,34,35)$. Moreover, this field of research has been primarily focused on women $(28,38-40,42)$ and on individuals with overweight or obesity $(12,15-20)$. In contrast, this current study is the first known study to investigate the specific healthy and unhealthy weight control behaviours associated with experiencing WBI in a sample of both men and women from three objectively measured weight statuses.

The secondary objective of this study was to examine the relationship between weight perception (underestimation, overestimation and accurate estimation) and the healthy and unhealthy weight control behaviours. It was originally hypothesized that weight underestimation would be positively associated with the number of healthy weight control behaviours, but negatively associated with the number of unhealthy and extreme behaviours. Additionally, we hypothesized that weight overestimation would be negatively associated with the number of healthy weight control behaviours, but positively associated with the number of unhealthy and extreme weight control behaviours. This study found no significant relationships between weight perception and weight control behaviours; however, several trends should be noted. Within the total sample population, the trend throughout the results suggested, that consistent with our hypothesis, weight underestimation was associated with an increase in the number of healthy weight control behaviours, as well as both additive and restrictive healthy weight control behaviours. Moreover, weight underestimation was negatively associated with the combined total number of unhealthy and extreme weight control behaviours, as well as unhealthy and extreme weight control behaviours individually. In contrast to our hypothesis, weight overestimation was associated with an increase in all aspects of both healthy and unhealthy/extreme weight control behaviours. Despite the fact that none of these results were statistically significant, we highlighted these trends so that future studies could further investigate how one's weight perception is associated with behaviours that individuals may engage in to control their weight.

This study detailed the specific types of weight control behaviours that are more likely to be performed in men versus women, and several important sex differences were detected. Determining sex differences was the tertiary objective of this study and it was hypothesized that mean WBI scores would be higher in women compared to men. Moreover, it was hypothesized 
that weight underestimation and accurate estimation would be higher among men compared to women and that women would perform more of each weight control behaviour compared to men. The results from this study suggest that mean WBI was higher in women compared to men, although it was not statistically different. In terms of the sex differences in weight perception classifications, results were consistent with the hypothesis that more women would overestimate their weight and more men would be classified as experiencing weight underestimation.

However, unlike previous research, in this current study, more women accurately estimated their weight status than men. Results were also consistent with another aspect of our hypothesis that women would perform more of each weight control behaviour compared to men. However, men did perform more unhealthy weight control behaviours compared to women, although the combination of unhealthy and extreme weight control behaviours was greater in women compared to men. This may have been primarily due to the fact that women performed significantly more extreme weight control behaviours compared to men.

The relationship between mean WBI and the number of additive healthy weight control behaviours was only significant among women. The additive healthy weight control behaviours included performing exercise and eating more fruits and vegetables. Further partitioning the healthy weight control behaviours into additive and restrictive behaviours was done in order to better understand the behavioural decisions individuals made in order to control their weight in a healthy manner. These results demonstrated that WBI was associated with healthy behaviours that individuals had to add to their lives in order to control weight, rather than behaviours that had to be removed or restricted. Women also had an increased likelihood of performing at least one extreme weight control behaviour, whereas this relationship was not observed in men. In terms of specific unhealthy weight control behaviours, mean WBI was significantly associated with skipping meals in women and eating little amounts of food in men. The results of this study support previous findings that extreme weight control behaviours are more common among women compared to men $(59,65-67)$. From studies performed in adolescent populations, researchers have speculated that experiencing weight stigmatization and having fears of being devalued as a person within society may increase one's motivation to escape these stigmatizing circumstances by engaging in unhealthy or disordered eating behaviours (68). Future research should conduct qualitative studies to better understand motivators for engaging in unhealthy weight control behaviours and if they relate to WBI. Women are also generally more likely than 
their male counterparts to experience stigmatization due to their weight (69). Elevated levels of WBI among women compared to men may be rooted in the idea that women are generally at a higher risk of experiencing weight bias due to the current sociocultural ideals surrounding beauty and thinness (70). This may increase women's sensitivity and awareness of encountering weight bias, ultimately increasing the likelihood of experiencing feelings of self-blame and internalization $(19,70)$.

The sensitivity analysis reassessed these relationships after removing participants with BMI values within $1 \mathrm{~kg} / \mathrm{m} 2$ of the BMI classification cut-off values. Although the BMI cut-off values have been utilized to assign disease risk to patients such as type II diabetes, hypertension and cardiovascular disease (63), BMI categorization may oversimplify the complete scope of a person's health. The values may not be biologically linked as a cut-off applicable to everyone. As BMI is a continuous measure, classifications (such as normal weight) may induce error, especially for those with BMI values near the classification cut-offs. Thus, eliminating those with BMI values within close proximity to the BMI classification cut-off values may reduce misclassification. The sensitivity analyses would therefore be more sensitive to detecting true discrepancies between objective and subjective weight status, rather than inaccurate relationships partly based on measurement error. Out of the 48 excluded participants, $54 \%$ accurately perceived their weight status $(\mathrm{N}=26)$, whereas $62 \%(\mathrm{~N}=100)$ participants from the entire original sample accurately perceived their weight status. It is unknown whether these cases of weight misperception stem from the general limitations of BMI as a crude measure, or whether it is due to inaccurate weight perceptions. For example, those with increased muscularity may be classified by BMI as an individual with overweight or obesity due to an elevated body weight but may perceive themselves as being "about the right weight". Based on the methods utilized in this study and throughout the literature, this individual would be classified as demonstrating weight underestimation. However, the reason for this individual's weight misclassification is likely rooted in BMI's inability to differentiate between muscle and fat mass, and not due to discrepancies in how this individual perceived his or her body.

Regardless of the precise reason behind an individual's weight status misclassification, weight perception has been shown to be associated with mental health correlates. For example, in a sample of Brazilian adults with and without obesity $(\mathrm{N}=1,238 ; 55.5 \%$ women; $23 \%$ with obesity (self-reported height and weight)), having obesity and perceiving one's self as having 
obesity significantly increased the likelihood of having depression, compared to those who did not have obesity and did not perceive themselves as having obesity (71). One's subjective weight status is highly related to one's body image. According to the National Eating Disorders Association, body image includes "how you feel about your body, including your height, shape, and weight" (72). Negative body image or body dissatisfaction has also been shown to be strongly associated with the development and maintenance of eating disorders such as anorexia nervosa and bulimia nervosa (73). These results suggest that perceiving one's self as having overweight or obesity may be detrimental to one's mental health and the ability to control one's weight in a healthy manner.

Upon comparing the results obtained from the primary analysis and those obtained in the sensitivity analysis, similarities were present. The same significant relationships were present for the relationship between mean WBI and the total number of healthy and unhealthy weight control behaviours performed. In addition to the fact that a majority of the relationships remained statistically significant, all of the results were similar in magnitude and direction compared to those obtained within the primary analyses. The results obtained from the primary analysis are strengthened because the sensitivity analysis showed similar findings despite a smaller sample size. However, mean WBI was no longer significantly associated with an increased likelihood of performing physical activity for weight control. This discrepancy is likely due to a decrease in sample size from the primary analysis with the full sample compared to the smaller sample used for the sensitivity analysis. In terms of the direct relationship between weight misperception and weight control behaviours, the sensitivity analysis was consistent with the main findings. These findings suggest that weight status misclassification did not largely impact the results obtained in the primary analysis using the full sample.

This work is not without its limitations. For instance, a lack of significant results may be attributed to a relatively small sample size and inadequate statistical power on certain analyses. With a larger sample size, researchers could stratify by both sex and weight perception group. For example, researchers would be able to identify the specific weight control behaviours among women who overestimate their weight or men who underestimate their weight. Further research could provide more information to guide patients or clients who fit within specific weight perception categories. Secondly, it is likely that some of the non-significant results may be attributed to the fact that the questionnaire used in this study did not investigate the full scope of 
possible weight control behaviours. For example, future research could examine excessive or compulsive exercise as a potential unhealthy weight control behaviour considering that it has been classified as a potentially harmful lifestyle behaviour linked to disordered eating symptomology (74). Previous research has also investigated additional healthy weight control behaviours such as commencing a low-carb diet or joining a commercial weight loss program (61). Another potential questionnaire that could have been utilized is the Weight Control Strategies Scale (WCSS), which assesses aspects such dietary choices, self-monitoring strategies, physical activity and psychological coping (75). The WCSS questionnaire asks about more varied options for weight control behaviours and how attempting to control one's weight impacts certain lifestyle behaviours. It goes into greater depth assessing not only the specific weight control behaviours, but also certain psychological aspects surrounding weight control. It discusses specific aspects such as food quality choices, compensatory behaviours and weight monitoring behaviours that individuals perform when attempting to control their weight. For example, one of the items of this questionnaire is "I ate meats, fish, or vegetables that were baked, broiled, or grilled". The relationship between WBI and the components of this questionnaire would be important to understand so that researchers could better comprehend other weight control behaviours that may or may not be interrupted or impeded by experiencing devaluing sentiments of WBI.

This research has many practical applications in healthcare and clinical settings. The current study highlighted that WBI is related to healthy and unhealthy weight control behaviours. Given that WBI is associated with weight control behaviours, future research should investigate its potential role in weight management outcomes to assess who may benefit from support to reduce the severity of internalization. Although future research is needed to better understand the role of WBI in weight management outcomes, health professionals should also be informed about the potential role that WBI has on patient's potential utilization of healthy and unhealthy weight control behaviours. If WBI is at the root of the pursuit of unhealthy weight control practices, treatment may be directed at mental health interventions to help address WBI. Future research should also investigate the role of weight perception and WBI in relation to weight control behaviours to better understand the role that weight perception may have in motivating individuals to undertake certain weight control behaviours. Future research should also assess how WBI changes over time. For example, investigating instances of childhood weight 
stigmatization or longitudinal studies among adolescents with or without WBI could also provide more information regarding how WBI is associated with weight control behaviours over an individual's lifetime. Additionally, future research could also investigate the relationship between WBI and weight control behaviours in a sample of individuals who previously had overweight or obesity. This would provide researchers with added information regarding how WBI is associated with the types of sustained and effective weight control behaviours. All of these aforementioned research suggestions could enhance our understanding of how WBI is associated with weight control and the various health correlates that strengthen or weaken this relationship. Additional research is ultimately needed in order to better understand why those with high WBI engage in certain types of weight control behaviours, while those with low WBI may engage in different ones. This added knowledge surrounding the various weight management correlates surrounding WBI may eventually lead to the improvement and effectiveness of targeted weight management protocols. If health professionals are better informed on the types of behaviours individuals with WBI are performing to control their weight, the more likely they will be able to manage and reduce them.

The results obtained in this study provide a better understanding regarding the behavioural correlates associated with experiencing WBI. This newly acquired knowledge adds to previous research in the field by enriching our knowledge on WBI and its health correlates and highlighting important future research avenues to better understand its potential role in weight management outcomes and interventions. 


\section{CHAPTER 5: CONCLUSION}

This thesis describes the results obtained from the first known study to examine the relationship between WBI and healthy and unhealthy weight control behaviours in both men and women of three objectively measured weight statuses.

This research demonstrates that WBI is related to certain weight control behaviours. Although further research is needed to determine if WBI is driving the pursuit of these weight control behaviours and weight management outcomes, WBI could be considered in routine healthcare screening protocols for patients and clients engaged in weight management programs. Future studies on WBI could have clinical implications regarding how health professionals counsel patients seeking weight management.

An improved understanding of WBI could potentially have implications for how weight management is discussed between healthcare professionals and patients. Future research might suggest the importance of healthcare professionals being informed and being able to discuss how experiencing WBI and sentiments of self-devaluation because of one's weight may have adverse effects on healthy weight control behaviours. However, more research is needed to understand how discussing WBI with patients is associated with changes in levels of WBI, and how having an open discussion regarding WBI may impact achieving weight control in a healthy manner. A recent study demonstrated that physicians discussing a patient's weight in a supportive manner can significantly positively impact the patient's health motivation, compliance and willingness to see a physician, compared to discussing weight in a stigmatizing manner (76). Thus, it is important that physicians continue to discuss aspects surrounding weight management in a nonstigmatizing manner.

In order to obtain a better understanding of the health impacts of weight bias and WBI, additional research is needed. It is recommended that researchers include representative samples of individuals across the entire weight spectrum because as this thesis demonstrated, weight bias, WBI and unhealthy weight control behaviours are not exclusive to individuals living in large bodies. In order to effectively reduce WBI through educational efforts and public health messaging in the future, further research on the underlying mechanisms and health consequences of WBI is needed. Although this study is cross-sectional, the obtained results provide a

preliminary understanding regarding how internalizing weight bias and agreeing with the 
negative stereotypes surrounding individuals with overweight and obesity, can be associated with behaviours that individuals perform in order to control their weight.

As mounting evidence of the negative mental health impacts of WBI suggests that weight bias may become a major public health problem, more research is needed alongside public health and educational initiatives in order to reduce the prominence of weight bias in all aspects of society. The future of weight bias and WBI research should include interdisciplinary teams of researchers from both physical and mental health fields, alongside policy makers, educators and epidemiologists in order better understand the potential role of WBI in weight management outcomes and interventions. 


\section{REFERENCES}

1. Bancej C, Jayabalasingham B, Wall RW, Rao DP, Do MT, de Groh M, et al. Trends and projections of obesity among Canadians. Health Promot Chronic Dis Prev Can. 2015 Sep;35(7):109-12.

2. Puhl RM, Latner JD, O’Brien K, Luedicke J, Danielsdottir S, Forhan M. A multinational examination of weight bias: predictors of anti-fat attitudes across four countries. Int J Obes (Lond). 2015 Jul;39(7):1166-73.

3. Puhl RM, Heuer CA. The stigma of obesity: a review and update. Obesity (Silver Spring). 2009 May;17(5):941-64.

4. Savoy S, Boxer P. The impact of weight-biased media on weight attitudes, self-attitudes, and weight-biased behavior. Psychology of Popular Media. 2020;9(1):31-44.

5. Ata RN, Thompson JK. Weight Bias in the Media: A Review of Recent Research. OFA. 2010;3(1):41-6.

6. Hussin M, Frazier S, Thompson J. Fat Stigmatization on YouTube: A Content Analysis. Body Image. 2011 Jan 1;8(1):90-2.

7. Hilbert A, Ried J. Obesity in print: an analysis of daily newspapers. Obes Facts. 2009;2(1):46-51.

8. Jackson SE, Beeken RJ, Wardle J. Perceived weight discrimination and changes in weight, waist circumference, and weight status. Obesity (Silver Spring). 2014 Dec;22(12):2485-8.

9. Emmer C, Bosnjak M, Mata J. The association between weight stigma and mental health: A meta-analysis. Obesity Reviews. 2020;21(1):e12935.

10. Puhl R, Suh Y. Health Consequences of Weight Stigma: Implications for Obesity Prevention and Treatment. Curr Obes Rep. 2015 Jun 1;4(2):182-90.

11. Alberga AS, Russell-Mayhew S, von Ranson KM, McLaren L. Weight bias: a call to action. Journal of Eating Disorders. 2016 Nov 7;4(1):34.

12. Pearl RL, Puhl RM. Weight bias internalization and health: a systematic review. Obes Rev. 2018;19(8):1141-63.

13. Han S, Agostini G, Brewis AA, Wutich A. Avoiding exercise mediates the effects of internalized and experienced weight stigma on physical activity in the years following bariatric surgery. BMC Obesity. 2018 Jul 2;5(1):18.

14. Durso LE, Latner JD. Understanding self-directed stigma: development of the weight bias internalization scale. Obesity (Silver Spring). 2008 Nov;16 Suppl 2:S80-86. 
15. Puhl RM, Himmelstein MS, Quinn DM. Internalizing Weight Stigma: Prevalence and Sociodemographic Considerations in US Adults. Obesity (Silver Spring). 2018;26(1):16775 .

16. Pearl RL, Himmelstein MS, Puhl RM, Wadden TA, Wojtanowski AC, Foster GD. Weight bias internalization in a commercial weight management sample: prevalence and correlates. Obesity Science \& Practice. 2019;5(4):342-53.

17. Boswell RG, White MA. Gender differences in weight bias internalisation and eating pathology in overweight individuals. Adv Eat Disord. 2015;3(3):259-68.

18. Pearl RL, White MA, Grilo CM. Overvaluation of shape and weight as a mediator between self-esteem and weight bias internalization among patients with binge eating disorder. Eat Behav. 2014 Apr;15(2):259-61.

19. Pearl RL, Puhl RM. Measuring internalized weight attitudes across body weight categories: validation of the modified weight bias internalization scale. Body Image. 2014 Jan;11(1):8992.

20. Schvey NA, Roberto CA, White MA. Clinical correlates of the Weight Bias Internalization Scale in overweight adults with binge and purge behaviours. Advances in Eating Disorders. 2013 Nov 1;1(3):213-23.

21. Schvey NA, White MA. The internalization of weight bias is associated with severe eating pathology among lean individuals. Eat Behav. 2015 Apr;17:1-5.

22. Lillis J, Thomas JG, Levin ME, Wing RR. Self-stigma and weight loss: The impact of fear of being stigmatized. J Health Psychol. 2017 Nov 6;1359105317739101.

23. Weineland S, Lillis J, Dahl J. Measuring experiential avoidance in a bariatric surgery population--psychometric properties of AAQ-W. Obes Res Clin Pract. 2013 Dec;7(6):e464475.

24. Pearl RL, Puhl RM. The distinct effects of internalizing weight bias: An experimental study. Body Image. 2016 Jun;17:38-42.

25. Durso LE, Latner JD, White MA, Masheb RM, Blomquist KK, Morgan PT, et al. Internalized weight bias in obese patients with binge eating disorder: associations with eating disturbances and psychological functioning. Int J Eat Disord. 2012 Apr;45(3):423-7.

26. Durso LE, Latner JD, Ciao AC. Weight bias internalization in treatment-seeking overweight adults: Psychometric validation and associations with self-esteem, body image, and mood symptoms. Eat Behav. 2016;21:104-8.

27. Pearl RL, White MA, Grilo CM. Weight bias internalization, depression, and self-reported health among overweight binge eating disorder patients. Obesity (Silver Spring). 2014 May;22(5):E142-148. 
28. Schvey NA, Sbrocco T, Bakalar JL, Ress R, Barmine M, Gorlick J, et al. The Experience of Weight Stigma Among Gym Members With Overweight and Obesity. Stigma and Health. 2017;2(4):292-306.

29. Hain B, Langer L, Hünnemeyer K, Rudofsky G, Zech U, Wild B. Translation and validation of the German version of the weight self-stigma questionnaire (WSSQ). Obes Surg. 2015 Apr;25(4):750-3.

30. Lent MR, Napolitano MA, Wood GC, Argyropoulos G, Gerhard GS, Hayes S, et al. Internalized weight bias in weight-loss surgery patients: psychosocial correlates and weight loss outcomes. Obes Surg. 2014 Dec;24(12):2195-9.

31. Pearl RL, Wadden TA, Chao AM, Walsh O, Alamuddin N, Berkowitz RI, et al. Weight Bias Internalization and Long-Term Weight Loss in Patients With Obesity. Ann Behav Med. 2019 Jul 17;53(8):782-7.

32. Wang SB, Lydecker JA, Grilo CM. Rumination in Patients with Binge-Eating Disorder and Obesity: Associations with Eating-Disorder Psychopathology and Weight-bias Internalization. Eur Eat Disord Rev. 2017;25(2):98-103.

33. Puhl RM, Quinn DM, Weisz BM, Suh YJ. The Role of Stigma in Weight Loss Maintenance Among U.S. Adults. Ann Behav Med. 2017 Oct;51(5):754-63.

34. Vartanian LR, Pinkus RT, Smyth JM. Experiences of weight stigma in everyday life: Implications for health motivation. Stigma and Health. 2018;3(2):85-92.

35. Koball AM, Mueller PS, Craner J, Clark MM, Nanda S, Kebede EB, et al. Crucial conversations about weight management with healthcare providers: patients' perspectives and experiences. Eat Weight Disord. 2018 Feb;23(1):87-94.

36. Himmelstein MS, Puhl RM, Quinn DM. Intersectionality: An Understudied Framework for Addressing Weight Stigma. Am J Prev Med. 2017 Oct;53(4):421-31.

37. Yaemsiri S, Slining MM, Agarwal SK. Perceived weight status, overweight diagnosis, and weight control among US adults: the NHANES 2003-2008 Study. Int J Obes (Lond). 2011 Aug;35(8):1063-70.

38. Hübner C, Baldofski S, Zenger M, Tigges W, Herbig B, Jurowich C, et al. Influences of general self-efficacy and weight bias internalization on physical activity in bariatnc surgery candidates. Surgery for Obesity and Related Diseases. 2014 Nov 25;11.

39. Mensinger JL, Meadows A. Internalized weight stigma mediates and moderates physical activity outcomes during a healthy living program for women with high body mass index. Psychology of Sport and Exercise. 2017;30:64-72.

40. Pearl RL, Puhl RM, Dovidio JF. Differential effects of weight bias experiences and internalization on exercise among women with overweight and obesity. J Health Psychol. 2015 Dec;20(12):1626-32. 
41. Levy M. Weight Bias Internalization: Sex Differences and Relationship to Physical Activity and Sedentary Behaviour. Oral \& Poster Presentation presented at: 6th Canadian Obesity Summit; 2019 May 24; Ottawa, Ontario.

42. Vartanian LR, Novak SA. Internalized societal attitudes moderate the impact of weight stigma on avoidance of exercise. Obesity (Silver Spring). 2011 Apr;19(4):757-62.

43. Purton T, Mond J, Cicero D, Wagner A, Stefano E, Rand-Giovannetti D, et al. Body dissatisfaction, internalized weight bias and quality of life in young men and women. Qual Life Res. 2019 Jul;28(7):1825-33.

44. Lee MS, Dedrick RF. Weight Bias Internalization Scale: Psychometric properties using alternative weight status classification approaches. Body Image. 2016 Jun;17:25-9.

45. Haynes A, Kersbergen I, Sutin A, Daly M, Robinson E. A systematic review of the relationship between weight status perceptions and weight loss attempts, strategies, behaviours and outcomes. Obesity Reviews. 2018;19(3):347-63.

46. Duncan DT, Wolin KY, Scharoun-Lee M, Ding EL, Warner ET, Bennett GG. Does perception equal reality? Weight misperception in relation to weight-related attitudes and behaviors among overweight and obese US adults. Int J Behav Nutr Phys Act. 2011 Mar 22;8:20.

47. Sonneville KR, Thurston IB, Milliren CE, Gooding HC, Richmond TK. Weight misperception among young adults with overweight/obesity associated with disordered eating behaviors. Int J Eat Disord. 2016 Oct;49(10):937-46.

48. Park B, Cho HN, Choi E, Seo DH, Kim N-S, Park E, et al. Weight control behaviors according to body weight status and accuracy of weight perceptions among Korean women: a nationwide population-based survey. Scientific Reports. 2019 Jun 24;9(1):9127.

49. Voelker DK, Reel JJ, Greenleaf C. Weight status and body image perceptions in adolescents: current perspectives. Adolesc Health Med Ther. 2015 Aug 25;6:149-58.

50. LaRose JG, Leahey TM, Hill JO, Wing RR. Differences in motivations and weight loss behaviors in young adults and older adults in the National Weight Control Registry. Obesity (Silver Spring). 2013 Mar;21(3):449-53.

51. Lim H, Wang Y. Body weight misperception patterns and their association with healthrelated factors among adolescents in South Korea. Obesity (Silver Spring). 2013 Dec;21(12):2596-603.

52. Martin BC, Dalton WT, Williams SL, Slawson DL, Dunn MS, Johns-Wommack R. Weight status misperception as related to selected health risk behaviors among middle school students. J Sch Health. 2014 Feb;84(2):116-23. 
53. Cheung P, Ip P, Lam S, Bibby H. A study on body weight perception and weight control behaviours among adolescents in Hong Kong. Hong Kong medical journal = Xianggang yi xue za zhi / Hong Kong Academy of Medicine. 2007 Mar 1;13:16-21.

54. Nagata JM, Garber AK, Tabler JL, Murray SB, Bibbins-Domingo K. Differential Risk Factors for Unhealthy Weight Control Behaviors by Sex and Weight Status Among U.S. Adolescents. J Adolesc Health. 2018;63(3):335-41.

55. Ursoniu S, Putnoky S, Vlaicu B. Body weight perception among high school students and its influence on weight management behaviors in normal weight students: a cross-sectional study. Wien Klin Wochenschr. 2011 Jun;123(11-12):327-33.

56. Zhang J, Feng X, Zhai Y, Li W, Lv Y-B, Astell-Burt T, et al. Clustering of unhealthy lifestyle behaviours and associations with perceived and actual weight status among primary school children in China: A nationally representative cross-sectional study. Prev Med. 2018;112:6-14.

57. McDermott C, Morrell JS. Perceived Weight Status Among College Students and Its Relationship with Life Satisfaction (FS10-08-19). Curr Dev Nutr [Internet]. 2019 Jun 1 [cited 2020 Apr 10];3(Supplement_1). Available from: https://academic.oup.com/cdn/article/3/Supplement_1/nzz039.FS10-08-19/5516662

58. Datar A, Chung PJ. Accuracy of Weight Perceptions in a Nationally Representative Cohort of US 8th Grade Adolescents. Acad Pediatr. 2016 Apr;16(3):267-74.

59. Kim Y, Austin SB, Subramanian SV, Kawachi I. Body weight perception, disordered weight control behaviors, and depressive symptoms among Korean adults: The Korea National Health and Nutrition Examination Survey 2014. PLoS ONE. 2018;13(6):e0198841.

60. Harring HA, Montgomery K, Hardin J. Perceptions of body weight, weight management strategies, and depressive symptoms among US college students. J Am Coll Health. 2010;59(1):43-50.

61. Lemon SC, Rosal MC, Zapka J, Borg A, Andersen V. Contributions of weight perceptions to weight loss attempts: differences by body mass index and gender. Body Image. 2009 Mar;6(2):90-6.

62. Neumark-Sztainer D, Wall MM, Larson N, Story M, Fulkerson JA, Eisenberg ME, et al. Secular trends in weight status and weight-related attitudes and behaviors in adolescents from 1999 to 2010. Prev Med. 2012 Jan;54(1):77-81.

63. Losing Weight, Body Mass Iindex [Internet]. [cited 2020 Jun 10]. Available from: https://www.nhlbi.nih.gov/health/educational/lose_wt/BMI/bmi_dis

64. Okorodudu DO, Jumean MF, Montori VM, Romero-Corral A, Somers VK, Erwin PJ, et al. Diagnostic performance of body mass index to identify obesity as defined by body adiposity: a systematic review and meta-analysis. Int J Obes (Lond). 2010 May;34(5):791-9. 
65. Neumark-Sztainer D, Rock CL, Thornquist MD, Cheskin LJ, Neuhouser ML, Barnett MJ. Weight-control behaviors among adults and adolescents: associations with dietary intake. Prev Med. 2000 May;30(5):381-91.

66. Neumark-Sztainer D, Story M, Hannan PJ, Perry CL, Irving LM. Weight-related concerns and behaviors among overweight and nonoverweight adolescents: implications for preventing weight-related disorders. Arch Pediatr Adolesc Med. 2002 Feb;156(2):171-8.

67. Weiss EC, Galuska DA, Khan LK, Serdula MK. Weight-control practices among U.S. adults, 2001-2002. Am J Prev Med. 2006 Jul;31(1):18-24.

68. Hunger JM, Major B, Blodorn A, Miller CT. Weighed down by stigma: How weight-based social identity threat contributes to weight gain and poor health. Soc Personal Psychol Compass. 2015 Jun;9(6):255-68.

69. Sattler KM, Deane FP, Tapsell L, Kelly PJ. Gender differences in the relationship of weightbased stigmatisation with motivation to exercise and physical activity in overweight individuals. Health Psychol Open. 2018 Jun;5(1):2055102918759691.

70. Puhl RM, Andreyeva T, Brownell KD. Perceptions of weight discrimination: prevalence and comparison to race and gender discrimination in America. Int J Obes (Lond). 2008 Jun;32(6):992-1000.

71. Paulitsch RG, Demenech LM, Dumith SC. Association of depression and obesity is mediated by weight perception. J Health Psychol. 2020 Jan 2;1359105319897778.

72. Body Image [Internet]. National Eating Disorders Association. Available from: https://www.nationaleatingdisorders.org/body-image-0

73. Lantz EL, Gaspar ME, DiTore R, Piers AD, Schaumberg K. Conceptualizing body dissatisfaction in eating disorders within a self-discrepancy framework: a review of evidence. Eat Weight Disord. 2018 Jun 1;23(3):275-91.

74. Berczik K, Szabó A, Griffiths MD, Kurimay T, Kun B, Urbán R, et al. Exercise Addiction: Symptoms, Diagnosis, Epidemiology, and Etiology. Substance Use \& Misuse. 2012 Feb 13;47(4):403-17.

75. Pinto AM, Fava JL, Raynor HA, LaRose JG, Wing RR. Development and Validation of the Weight Control Strategies Scale. Obesity (Silver Spring). 2013 Dec;21(12):2429-36.

76. Hayward LE, Neang S, Ma S, Vartanian LR. Discussing weight with patients with overweight: Supportive (not stigmatizing) conversations increase compliance intentions and health motivation. Stigma and Health. 20190506;5(1):53. 
APPENDIX

WEIGHT BIAS INTERNALIZATION SCALE (WBIS)

\begin{tabular}{|l|c|c|c|c|c|}
\hline & $\begin{array}{c}\text { Strongly } \\
\text { disagree } \\
\text { (1) }\end{array}$ & $\begin{array}{c}\text { Slightly } \\
\text { disagree } \\
\mathbf{( 2 )}\end{array}$ & $\begin{array}{c}\text { Neither } \\
\text { agree nor } \\
\text { disagreed } \\
\text { (3) }\end{array}$ & $\begin{array}{c}\text { Slightly } \\
\text { agree } \\
\text { (4) }\end{array}$ & $\begin{array}{c}\text { Strongly } \\
\text { agree } \\
\text { (5) }\end{array}$ \\
\hline $\begin{array}{l}\text { al. As an overweight person, I feel that I } \\
\text { am just as competent as anyone. }\end{array}$ & $\mathbf{1}$ & $\mathbf{2}$ & $\mathbf{3}$ & $\mathbf{4}$ & $\mathbf{5}$ \\
\hline $\begin{array}{l}\text { 2. I am less attractive than most other } \\
\text { people because of my weight. }\end{array}$ & $\mathbf{1}$ & $\mathbf{2}$ & $\mathbf{3}$ & $\mathbf{4}$ & $\mathbf{5}$ \\
\hline $\begin{array}{l}\text { 3. I feel anxious about being overweight } \\
\text { because of what people might think of } \\
\text { me. }\end{array}$ & $\mathbf{1}$ & $\mathbf{2}$ & $\mathbf{3}$ & $\mathbf{4}$ & $\mathbf{5}$ \\
\hline $\begin{array}{l}\text { 4. I wish I could drastically change my } \\
\text { weight. }\end{array}$ & $\mathbf{1}$ & $\mathbf{2}$ & $\mathbf{3}$ & $\mathbf{4}$ & $\mathbf{5}$ \\
\hline $\begin{array}{l}\text { 5. Whenever I think a lot about being } \\
\text { overweight, I feel depressed. }\end{array}$ & $\mathbf{1}$ & $\mathbf{2}$ & $\mathbf{3}$ & $\mathbf{4}$ & $\mathbf{5}$ \\
\hline $\begin{array}{l}\text { 6. I hate myself for being overweight. } \\
\text { 7. My weight is a major way that I judge } \\
\text { my value as a person. }\end{array}$ & $\mathbf{1}$ & $\mathbf{1}$ & $\mathbf{3}$ & $\mathbf{4}$ & $\mathbf{5}$ \\
\hline $\begin{array}{l}\text { 8. I don't feel that I deserve to have a } \\
\text { really fulfilling social life, as long as I'm } \\
\text { overweight. }\end{array}$ & $\mathbf{1}$ & $\mathbf{2}$ & $\mathbf{3}$ & $\mathbf{4}$ & $\mathbf{5}$ \\
\hline $\begin{array}{l}\text { a9. I am OK being the weight that I am. } \\
\text { 10. Because I'm overweight, I don't feel } \\
\text { like my true self. }\end{array}$ & $\mathbf{1}$ & $\mathbf{2}$ & $\mathbf{3}$ & $\mathbf{4}$ & $\mathbf{5}$ \\
\hline $\begin{array}{l}\text { 11. Because of my weight, I don't } \\
\text { understand how anyone attractive would } \\
\text { want to date me. }\end{array}$ & $\mathbf{1}$ & $\mathbf{2}$ & $\mathbf{3}$ & $\mathbf{4}$ & $\mathbf{5}$ \\
\hline
\end{tabular}

altem is reverse-scored. Items were scaled from 1 (Strongly disagree) to 5 (Strongly agree). 


\section{HEALTHY WEIGHT CONTROL BEHAVIOURS}

How often have you done each of the following things in order to lose weight or avoid gaining weight during the past year?

\begin{tabular}{|l|l|l|l|c|}
\hline 1. Exercise & Never & Rarely & Sometimes & Often \\
\hline 2. Ate more fruits and vegetables & Never & Rarely & Sometimes & Often \\
\hline 3. Ate less high-fat foods & Never & Rarely & Sometimes & Often \\
\hline 4. Ate less sweets & Never & Rarely & Sometimes & Often \\
\hline 5. Drank less soda pop (not including diet pop) & Never & Rarely & Sometimes & Often \\
\hline 6. Watched my portion sizes (serving sizes) & Never & Rarely & Sometimes & Often \\
\hline
\end{tabular}

\section{UNHEALTHY \& EXTREME WEIGHT CONTROL BEHAVIOURS}

Have you done any of the following things in order to lose weight or avoid gaining weight during the past year?

\begin{tabular}{|l|c|c|}
\hline 1. Fasted & Yes & No \\
\hline 2. Ate very little food & Yes & No \\
\hline 3. Took diet pills & Yes & No \\
\hline 4. Made myself vomit (throw up) & Yes & No \\
\hline 5. Used laxatives & Yes & No \\
\hline 6. Used diuretics & Yes & No \\
\hline 7. Used food substitute (powders/special drink) & Yes & No \\
\hline 8. Skipped meals & Yes & No \\
\hline 9. Smoked more cigarettes & Yes & \\
\hline
\end{tabular}




\section{Proof of Manuscript Submission to Obesity Facts}

Submission/Title/Type

Manuscript ID: ofa-2020-5-7

The Relationship between Weight Bias Internalization and Healthy and Unhealthy Weight Control Behaviours

Type: Research Article

Authors: Matthew Levy (Co-author), Lisa Kakinami (Co-author), Angela S.

[Author files]
Alberga (Corresponding Author)

Submitted: 2020-06-01
Status

In review 